\title{
GENDER EQUALITY AND FRAGILITY
}

Charlotte Goemans, Diana Koester and Seve Loudon
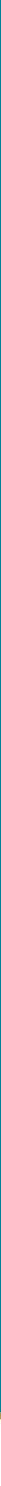

OECD DEVELOPMENT CO-OPERATION WORKING PAPER 98

Authorised for publication by Jorge Moreira da Silva, Director, Development Co-operation Directorate 



\section{Working Paper}

OECD Working Papers do not represent the official views of the OECD or of its member countries. The opinions expressed and arguments employed are those of the author(s).

Working Papers describe preliminary results or research in progress by the author(s) and are published to stimulate discussion on a broad range of issues on which the OECD works. Comments on this Working Paper are welcome and may be sent to DCD.GenderNet@oecd.org, Development Co-ordination Directorate, OECD, 2 rue André-Pascal, 75775 Paris Cedex 16, France.

This document, as well as any data and any map included herein, are without prejudice to the status of or sovereignty over any territory, to the delimitation of international frontiers and boundaries and to the name of any territory, city or area.

Please cite this paper as Goemans, C., D. Koester and S. Loudon (2021), "Gender equality and fragility", OECD Development Co-operation Working Papers, No. 98, OECD Publishing, Paris. 


\section{Abstract}

Gender equality and fragility are inextricably linked. Addressing issues of gender inequality in fragile contexts requires systematic approaches that work through the complexity of fragility. It requires contextual understanding of social norms, political sensitivities, environmental concerns, and other risks that continue to perpetuate fragility. The OECD Fragility Framework provides pathways to address those inequalities and to further understand the relevance of gender within each dimension. An analysis of gender equality within the fragility framework also highlights the far-reaching implications that gender-related issues have towards driving the root causes of conflict and beyond. As part of the 2020 States of Fragility series, this working paper unpacks the deep-rooted linkages between gender inequalities and fragility; provides an analysis of gender within the current Fragility Framework; and looks to areas of improvement for understanding and addressing these inequalities. The aim is to ultimately understand how gender equality factors may lead to better development outcomes and the prevention of conflict and fragility. 


\section{Acknowledgements}

This paper is a joint production of the Gender Equality and Women's Empowerment team and the Crises and Fragility team of the OECD Development Co-operation Directorate. It was written by Charlotte Goemans and Seve Loudon with inputs and support from Jonathan Marley, Harsh Desai, and Kathleen Forichon. Diana Koester drafted the original piece. This paper was prepared under the strategic guidance and leadership of Lisa Williams, Gender Equality and Women's Empowerment Team Lead, Cyprien Fabre, Crises and Fragility Team Lead, and Mayumi Endoh, Deputy Director and Acting Head of the Global Partnerships and Policies Division. 


\section{Table of contents}

$\begin{array}{ll}\text { Abstract } & 4\end{array}$

$\begin{array}{ll}\text { Acknowledgements } & 5\end{array}$

Executive summary $\quad 8$

1 The role of gender inequalities in shaping fragility 10

2 Gender and fragility: The OECD Fragility Framework 12

3 States of Fragility 2020: Trends in gender aspects of fragility 15

Situations that arise in fragile contexts can provide opportunities to promote women's
representation in parliament

There are considerable opportunities to address fragility by promoting women's equal
participation in the economy

Data suggests that fragile contexts may be marked by particularly permissive attitudes
towards male violence

Gender inequality and the gender aspects of fragility are not one issue but many 22

The scale of gender inequalities seen in many fragile contexts is rarely matched by dedicated resources

Global indicators must be complemented by careful contextual analysis in assessing gender relations as a part of fragility

Beyond adding individual variables, the gender aspects of fragility expand perspectives on fragility

COVID-19 and gender aspects of fragility

4 Conclusions $\quad 30$

References $\quad 31$

$\begin{array}{ll}\text { Notes } & 35\end{array}$

\section{FIGURES}

Figure 1.1. The relationship between fragility and gender inequality across the dimensions of fragility 
Figure 3.4. The ratio of female to male shares of employment in agriculture in different contexts in SubSaharan Africa

Figure 3.5. Ratio of female to male labour force participation over time in different contexts in South Asia

Figure 3.6. Ratio of female to male shares of employment in agriculture in different contexts in South Asia.

Figure 3.7. Percentage of women aged $15-49$ who consider a husband to be justified in hitting or beating his wife under at least one of several specific reasons

Figure 3.8. Strength of laws on violence against women and reproductive autonomy in fragile contexts in Latin America

Figure 3.9. Ratio of female to male labour force participation rate and proportion of seats held by women in national parliaments in fragile contexts in South Asia (2020)

Figure 3.10. The relationship between official development assistance to gender equality and women's

empowerment and the Gender Inequality Index in fragile contexts

Figure 3.11. Average number of gender-sensitive COVID-19 response measures introduced by fragile and other developing contexts in different areas

\section{TABLES}

Table 2.1. Overview of gender-specific indicators in the OECD Fragility Framework 


\section{Executive summary}

Gender inequalities have far-reaching implications. These inequalities affect the level of health care an individual might receive, the amount and quality of education, economic rights and empowerment, and the level of violence one might experience. The results of these inequalities are woven throughout societies and directly impact needs; often on a daily basis, and specifically with regard to gender. While gender equality can mitigate many risks, the opposite exposes fissures within society. Fissures, which become more profound within fragile and conflict-affected situations (FCAS). Gender inequalities perpetuate, and often cause, fragility.

The States of Fragility 2020 report (OECD, 2020[1]) has highlighted the increased risks that all nations face as a result of the COVID-19 pandemic. It also emphasises that while COVID-19 has exacerbated aspects of fragility ${ }^{1}$ globally, the 57 fragile contexts identified by the OECD Fragility Framework feel the brunt of this pandemic; on a humanitarian level, in terms of development, and certainly in terms of securitisation. Further, and in complement, to this, an in-depth review of gender equality within fragile contexts in needed; especially in light of COVID-19.

Towards that end, this paper highlights the interconnectedness of gender equality and fragility, showcasing how deep-rooted the linkages are. It also provides an in-depth look at gender equality and women's empowerment in fragile contexts using measures across the dimensions of fragility, and looks to areas of improvement for understanding and acting on these interconnected inequalities.

The paper identifies seven trends:

Opportunities exist to address fragility by promoting equal opportunities for women in the economy. By further integrating more than half the population, in many instances, into the labour force, many fragile contexts can deliver on their economic potential. However, while the inclusion of women into the economy might positively affect a number of indicators of fragility, restrictive social norms often play a significant role in limiting this integration.

Situations arising in fragile contexts can provide opportunities to promote women's representation in parliament. Situations where armed conflict is drawing to a close, or experiences of/transitions from conflict and fragility - such as peace negotiations, political transitions or constitution-making processes can provide openings to integrate quotas into foundational agreements. Such opportunities may not arise in more stable contexts.

Existing social norms are not solely a barrier to economic equality: they can act as a barrier to overall progress on gender equality. Notably, existing data suggests that FCAS may be marked by particularly permissive attitudes towards male violence. These attitudes, while not exclusive to fragile contexts, directly correlate to levels of gender-based violence and intimate partner violence. In areas of existing armed conflict, this is exacerbated even further.

Importantly, gender inequality and the gender-related aspects of fragility involve many challenges, e.g. rolling back gender-based violence, or promoting women's economic empowerment and political participation. Addressing these challenges to gender equality is a systematic process intertwined with the 
complexities of fragility. This means that many of the gender equality aspects of fragility are not uniform and vary from context to context. While the OECD Fragility Framework analyses specific gender-related indicators - such as the share of women in parliament - gender equality issues are applicable, and relevant, to the entire framework. Thus, developing further qualitative analysis of gender-related trends in fragile contexts may be a priority for future States of Fragility reports, in addition to incorporating gender equality into indicator descriptions within the framework.

On a practical level, the scale of gender inequalities seen in many fragile contexts is rarely matched by dedicated humanitarian, developmental, or peacekeeping/building resources that flow to those contexts. While it is clear that gender equality within fragile contexts is an important issue, resources must be mobilised to meet the varied needs between contexts. Fragile contexts with the highest rankings on gender inequality, do not necessarily receive most of the funding to address these inequalities.

As such, global fragility indicators must be complemented by careful contextual analysis in assessing gender relations as a part of fragility. To address gender equality as part of fragility, policy makers need a context-based analysis that incorporates gender sensitivities into risk analyses and responses. Failing to take gender into account precludes, not only, the chance to address fragility as a whole but limits all potential areas of progress from the outset of programme design. However, further guidance is needed to understand how to practically incorporate gender equality into risk and conflict analyses.

Gender equality issues are humanitarian issues. They are development issues, and they are most certainly issues that contribute heavily to building a peaceful society. In the past year and a half, COVID-19 has delivered a systematic shock and women and girls - especially in fragile contexts - are likely to be among the most vulnerable that are at risk of being left behind. Much like a deeper understanding of fragility is tied to an understanding of gender inequalities, a deeper insight into the effects of COVID-19 - worldwide or in fragile contexts alone - can only be seen, measured, and understood by incorporating gender-based analysis and response. 


\section{The role of gender inequalities in shaping fragility}

Gender and fragility are inextricably linked. These interlinkages run through the complexity of fragile and conflict-affected situations, and every dimension of gender equality - or inequality - has a direct impact on fragility as a whole system. The reverse is also true. Fragility exacerbates already existing inequalities, much like the COVID-19 pandemic has done worldwide. Gender inequality is no exception. Crises have a devastating effect on the most vulnerable - among which are women and girls - whether those crises are armed conflict, environmental, or pandemics.

While there is considerable awareness of the effects of conflict on women and girls, wider connections between gender inequality and fragility are rarely addressed in research and practice (OECD, 2017 [2]; OECD, $\left.2020_{[3]}\right){ }^{2}$ The OECD has integrated gender across the dimensions of its fragility framework and is therefore in a unique position to help address this gap. The framework specifically recognises that gender inequalities shape risks and coping capacities in relation to security, our societies, economies and political life (see Figure 1.1). It highlights that persistent gender inequalities play an important role in perpetuating fragility and stalling achievement of the Sustainable Development Goals (SDGs). Importantly, the COVID-19 pandemic is likely to aggravate these trends.

This working paper contributes to the States of Fragility 2020 report by analysing gender-related data emerging from the different dimensions of the OECD fragility framework in 2020 as well as data from other sources in further detail and exploring what they tell us about the role of gender inequalities in shaping fragility. Overall, the paper suggests that increased analysis of gender-related elements of fragility can make a significant contribution to the understanding of - and practical responses to fragility.

The paper first outlines the OECD Fragility Framework and the ways in which it reflects connections between gender and fragility. It then highlights several key trends emerging from gender-related data collected for the States of Fragility 2020 report. In particular, the paper points to opportunities to address fragility by advancing women's political representation and economic participation, calling attention to attitudes and norms related to violence in fragile settings as an area, which may merit further investigation. The data also indicates disconnects between the scale of gender-related fragility challenges and levels of aid dedicated to gender equality in different fragile settings. 
Figure 1.1. The relationship between fragility and gender inequality across the dimensions of fragility

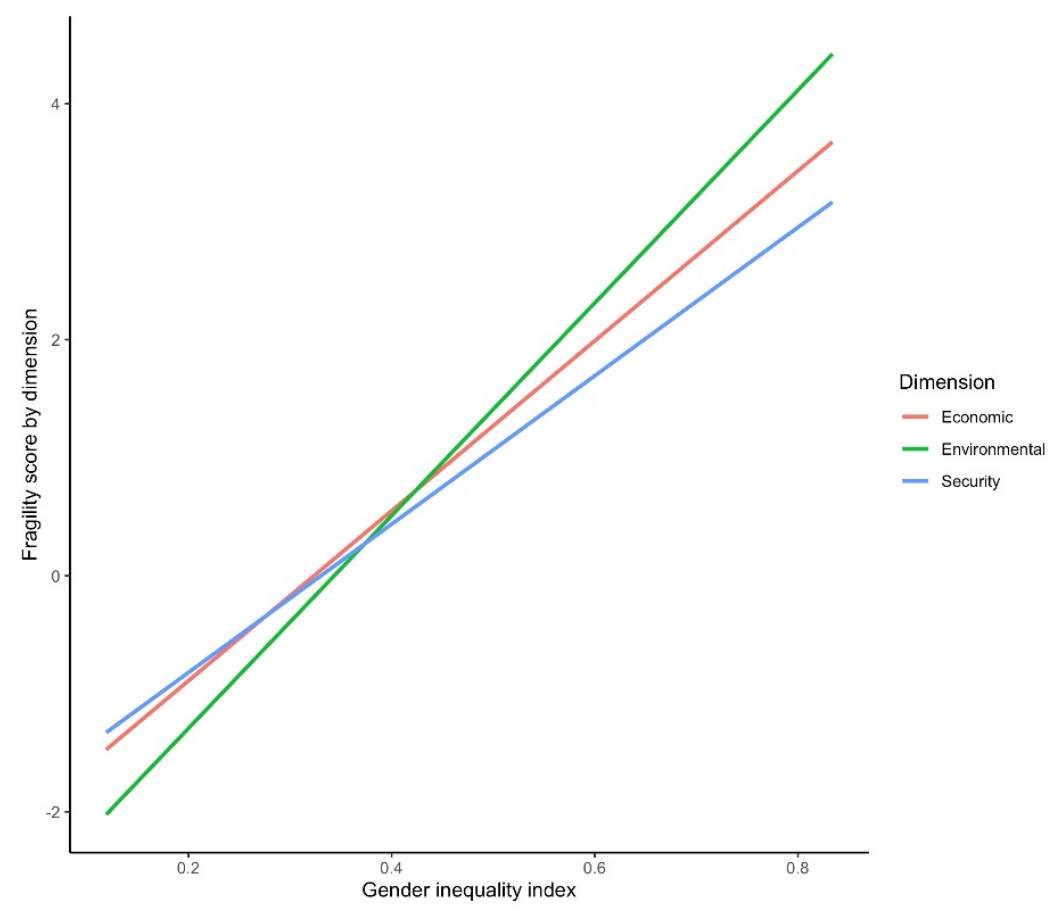

Note: This graph was originally produced in States of Fragility 2020. It examines the relationship between the gender inequality index ( $x$-axis) in 2018 (the latest year of data available at time of writing) and fragility across dimensions (y-axis), using the latest results of the OECD fragility framework and for all developing (ODA-eligible) countries for which data was available. Only dimensions of fragility that exhibited a strong relationship with gender inequality were included, and the societal dimension was excluded because the gender inequality index is one of the indicators used to measure fragility in the societal dimension.

Source: OECD (2020[1]), States of Fragility 2020, https://doi.org/10.1787/ba7c22e7-en.

The paper suggests that, beyond highlighting such practical challenges and opportunities, further analysis of gender dynamics can also enhance our overall understanding of fragility by drawing attention to a number of conceptual and methodological considerations. In particular, the paper shows that the challenges of gender inequality within fragility are not derived from one issue but many. Therefore, highlighting the significance of qualitative, contextual analysis and wider perspectives on fragility opened by examining gender aspects. While most of the 57 fragile contexts are marked by severe gender inequalities, the indicators suggest that the nature of these inequalities varies significantly from one fragile context to the next. As illustrated by the OECD's multidimensional approach to fragility, this nuanced approach is critical in both explaining and addressing global fragility. Additionally, a contextual analysis to understand the scale and nature of gender imbalances and inequalities that exist within a fragile context can even reinforce the effectiveness of aid.

The final section of the paper turns to the systemic shock experienced in 2020 - the COVID-19 pandemic - and the measures fragile contexts have taken to respond to the serious implications for women and girls. In light of these and other trends, gender aspects of fragility are a promising field for further research and engagement. 


\section{$\underline{2}$ Gender and fragility: The OECD Fragility Framework}

Fragility results from the combination of risk and insufficient coping capacity to manage, absorb, or mitigate those risks, which can lead to negative outcomes including: increases in violence, poverty, inequality, displacement, and environmental and political degradation (OECD, 2020[1]). Gender equality is a core component of understanding coping capacities, or lack thereof, within fragile contexts and the mitigation of those possible negative outcomes. Gender inequalities expose individuals and communities to significant risks while undermining the capacity of the state, systems and/or communities to manage, absorb or mitigate a wide range of risks. Gender inequality is therefore an important element of fragility.

Without taking into account the level of gender discrimination in a given context, it is impossible to account for critical risks faced by approximately $50 \%$ of the population - women and girls - or the capacity of the state, system and/or communities to address these risks. For example, the most common form of violence experienced by women and girls is sexual and gender-based violence. Around the globe, approximately 641 million women (27\% of ever-married/partnered women) have suffered either physical and/or sexual intimate partner violence $\left(\mathrm{WHO}, 2021_{[4]}\right)$. OECD calculations indicate that this percentage increases to $34 \%$ of ever-married/partnered women in fragile contexts and $39 \%$ in extremely fragile contexts, as compared to $26 \%$ in non-fragile developing countries ${ }^{3}$. However, these incidences of violence are probably higher given the fact that violence often goes unreported, especially in fragile contexts, and that many of these countries do not have recent data (UN Women, n.d. ${ }_{[5]}$ ). Discriminatory gender norms lie at the root of this violence. Without taking these into account, risks to women's physical integrity cannot be understood.

Gender inequalities also shape the extent to which states or communities manage or mitigate these and other risks faced by women. In many contexts, the primary reason for limited responses to women's specific concerns, including forms of violence that disproportionately affect them, is not a general lack of resources but gender inequality: the fact that many concerns that primarily affect women are not considered public priorities in the first place. Statistical research has, for instance, confirmed that levels of resources available to the state (GDP per capita) do not reliably predict the level of state responses to domestic and sexual violence. Instead, these are most strongly associated with the strength of women's autonomous civil society mobilisation, which can succeed in establishing the elimination of violence against women as part of the public agenda (Htun and Weldon, 2012[6]; Htun and Weldon, 2018[7] $)$.

While not sufficient to drive gender equality measures, the level of women's representation in public institutions can certainly help shape the responsiveness of the state or community to specific risks faced by women and girls. In addition to case studies demonstrating the efforts of female parliamentarians in selected countries, ${ }^{4}$ statistical research has found that, among other factors, larger proportions of women in parliament tend to have a positive relationship with the emergence of stronger gender equality policies in different areas, including policies to address violence against women (Htun and Weldon, 2018[7]). Global data also show a positive correlation between the presence of women police officers and reporting of sexual assault (UN Women, 2011 ${ }_{[8]}$; Schuck, 2018[9]). 
At the same time, gender inequalities can increase risks and reduce coping capacities for entire societies. While gender-based violence is an enormous burden for affected individuals, it also poses great societal costs, including through lost economic activity. Fearon and Hoeffler estimated physical intimate partner violence alone to have a cost corresponding to $5.2 \%$ of global GDP - more than political violence $(0.19 \%$ of global GDP) and interpersonal violence (homicides, $1.44 \%$ of global GDP) combined (Fearon and Hoeffler, 2014[10]). This cost corresponds to $11 \%$ in the Middle East and North Africa (MENA) and $15 \%$ in Sub-Saharan Africa (SSA), where 42 of the 57 fragile contexts are located (7 in MENA and 35 in SSA). Similarly, women's unequal participation in the economy, perpetuated by a wide range of gender inequalities, curtails economic growth. In 2015, the McKinsey Global Institute estimated that addressing these gaps could add up to USD 28 trillion, or 26\%, to global GDP by 2025 (McKinsey Global Institute, $\left.2015_{[11]}\right)$. The OECD estimates that the current level of gender discrimination induces a loss of almost USD 6000 billion, equivalent to 7.5\% of global income in 2017 (corresponding to approximately USD 1552 per capita) (OECD, 2020[12]).

Micro-level research in a range of conflict-affected contexts has confirmed that women's economic empowerment contributes positively to economic recovery after conflict (Justino et al., 2012[13]; Justino et al., 2012[14]]. Moreover, a range of studies point to connections between gender inequality, violence and conflict. In addition to driving gender-based violence, gender norms idealising male domination and aggression can encourage wider societal violence, including by facilitating recruitment of men into armed groups (OECD, 2019[15]; Wright, 2014[16] $)$. Women's meaningful participation in negotiations has in turn been found to increase the chances that peace agreements are reached and implemented (Paffenholz et al., 2015[17]; UN Women, 2015[18] $)$. Nevertheless, women are still largely left out of peace processes, especially in fragile contexts. Between 1992 and 2019, women made up only $13 \%$ of negotiators, $6 \%$ of mediators, and $6 \%$ of signatories, and seven out of ten peace processes did not include women mediators or signatories (Bigio et al., 2021 ${ }_{[19]}$ ). Women's limited participation in peace processes also reflects the lack of gender provisions in peace agreements since only a fifth of peace agreements refer to women (OECD, 2020[1]).

Quantitative research has also highlighted statistical associations between levels of gender inequality and societies' risk of conflict (Caprioli, 2005[20]; Caprioli and Boyer, 2001[21]; Demeritt, Nichols and Kelly, 2014[22]; Melander, 2005[23]). Moreover, many of these inequalities prevent women from fully contributing their skills and knowledge to effective and sustainable responses to climate-related challenges, while compounding the impacts on their lives. ${ }^{5}$

The OECD recognises such connections by considering a range of gender-specific indicators in its global assessment of fragility through the OECD fragility framework. It analyses the degree of fragility of different contexts across the economic, environmental, political, security and societal dimensions. The current fragility framework integrates gender-related indicators across four of these five dimensions (see Table 2.1). A sixth dimension, the human dimension, has been proposed to be added to the framework following the release of the States of Fragility 2020 report. 
Table 2.1. Overview of gender-specific indicators in the OECD Fragility Framework

\begin{tabular}{l|l|l}
\hline Dimension of Fragility & \multicolumn{1}{|c}{ Indicator } & \multicolumn{1}{c}{ Source } \\
\hline Economic fragility & Ratio of female to male participation in the labour force. & ILO. \\
\hline Political Fragility & Share of women in parliament. & $\begin{array}{l}\text { Inter-Parliamentary Union } \\
\text { (IPU). }\end{array}$ \\
\hline Security Fragility & $\begin{array}{l}\text { Restricted gender physical integrity index (as part of the Social Institutions } \\
\text { and Gender Index SIGI), capturing laws, attitudes and prevalence in relation } \\
\text { to sexual and domestic violence, FGM and reproductive autonomy. }\end{array}$ & OECD. \\
\hline Societal Fragility & $\begin{array}{l}\text { Gender Inequality Index, a composite measure reflecting inequality in } \\
\text { achievement between women and men and the loss of potential human } \\
\text { development due to inequality in achievement across three dimensions: } \\
\text { reproductive health, empowerment and the labour market. The GII is } \\
\text { composed of individual indicators on maternal mortality ratio, adolescent } \\
\text { birth rate, female and male population with at least secondary education, } \\
\text { female and male shares of parliamentary seats, and female and male labour } \\
\text { force participation rates. }\end{array}$ & UNDP. \\
\hline & \begin{tabular}{l} 
Does not yet include gender-specific indicators. \\
\hline Environmental Fragility
\end{tabular} & \\
\hline
\end{tabular}

Source: Overview of the OECD Fragility Framework and methodology can be found here: www3.compareyourcountry.org/states-offragility/overview/0/.

These indicators demonstrate specific examples and references to gender within the fragility framework but the relevance of gender equality within the framework is not solely captured within this set. For example, the data available for disaster risk - an indicator within the environmental dimension of fragility - while clearly relevant to defining environmental fragility, can also be highly relevant in understanding the nexus of gender inequalities and the dispersion of fragility.

As the OECD further develops the indicators to measure the human capital dimension of fragility, the relevance of a gender perspective within the fragility framework is increasingly important. Not least because the level of investment in human capital relates directly to establishing a people-centred approach in programme design that is fundamental to achieving gender equality (Forichon, 2020[24]). This includes the areas of education, reproductive health, and social protection, among others. 


\section{States of Fragility 2020: Trends in gender aspects of fragility}

\section{Situations that arise in fragile contexts can provide opportunities to promote women's representation in parliament}

The level of women's representation in parliaments varies considerably between the 57 fragile contexts. They range from some of the lowest levels of female parliamentary representation in the world in Papua New Guinea $(0 \%)$, Yemen $(0.3 \%)$ or Haiti $(2.5 \%)$ to the top of global rankings of numbers of women in parliament, in countries such as Nicaragua $(47.3 \%)$, Mozambique $(42.4 \%)$ or Ethiopia $(38.8 \%)$.

In extremely fragile contexts, levels of female parliamentary representation are especially varied and polarised. While half of the extremely fragile contexts include around $25 \%$ women and above in their parliaments, the other half include $15 \%$ female representation or significantly less - with nothing in between these two groups (see Figure 3.1).

Figure 3.1. Proportion of seats held by women in national parliaments (\%) in extremely fragile contexts

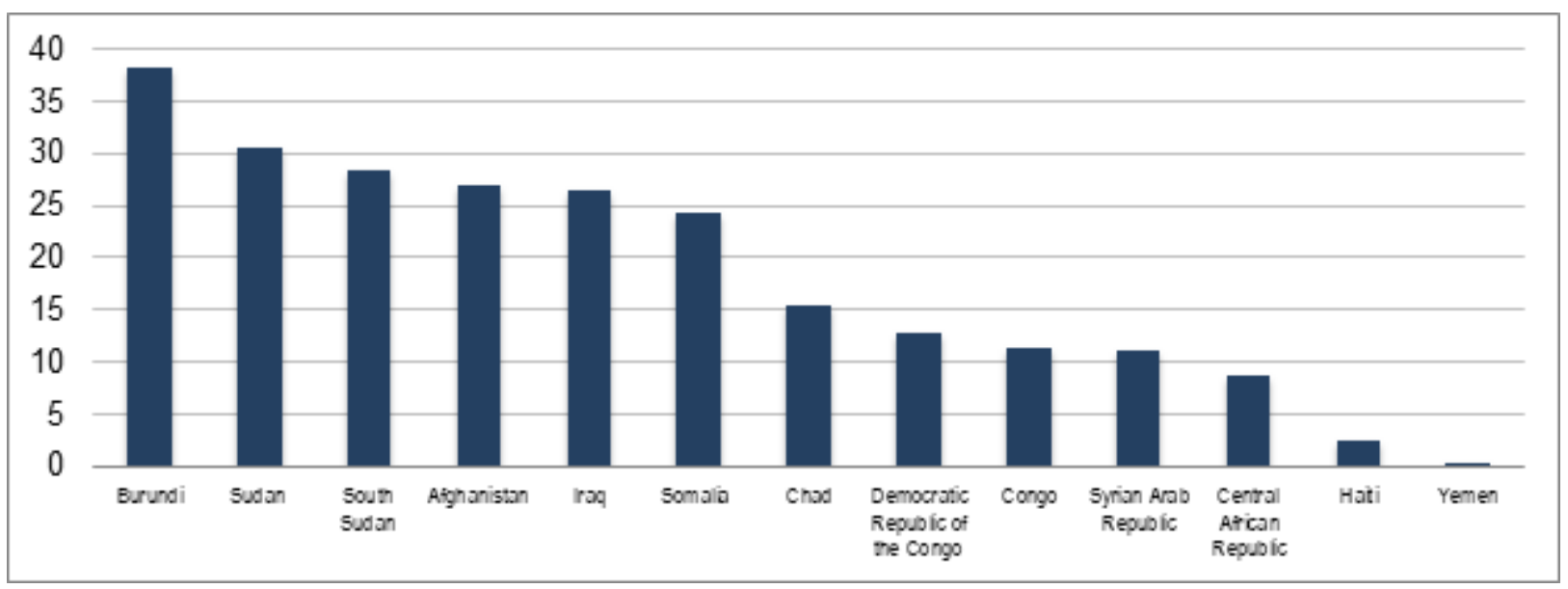

Note: Figures are for 2019 for Haiti, 2018 for Sudan, and 2020 for all other countries.

Source: Inter-Parliamentary Union (IPU).

There is also considerable variation in levels of female representation over time: some fragile contexts have experienced great leaps in women's political representation over the years. This includes some of the most fragile contexts, such as Burundi, Iraq, Somalia and Sudan. In the same time period, levels of female parliamentary representation in other extremely fragile contexts have stagnated or, in fact, declined further, such as Central African Republic, Haiti, and Yemen (see Figure 3.2). 
Figure 3.2. Trends in women's representation in parliament over time in selected extremely fragile contexts.

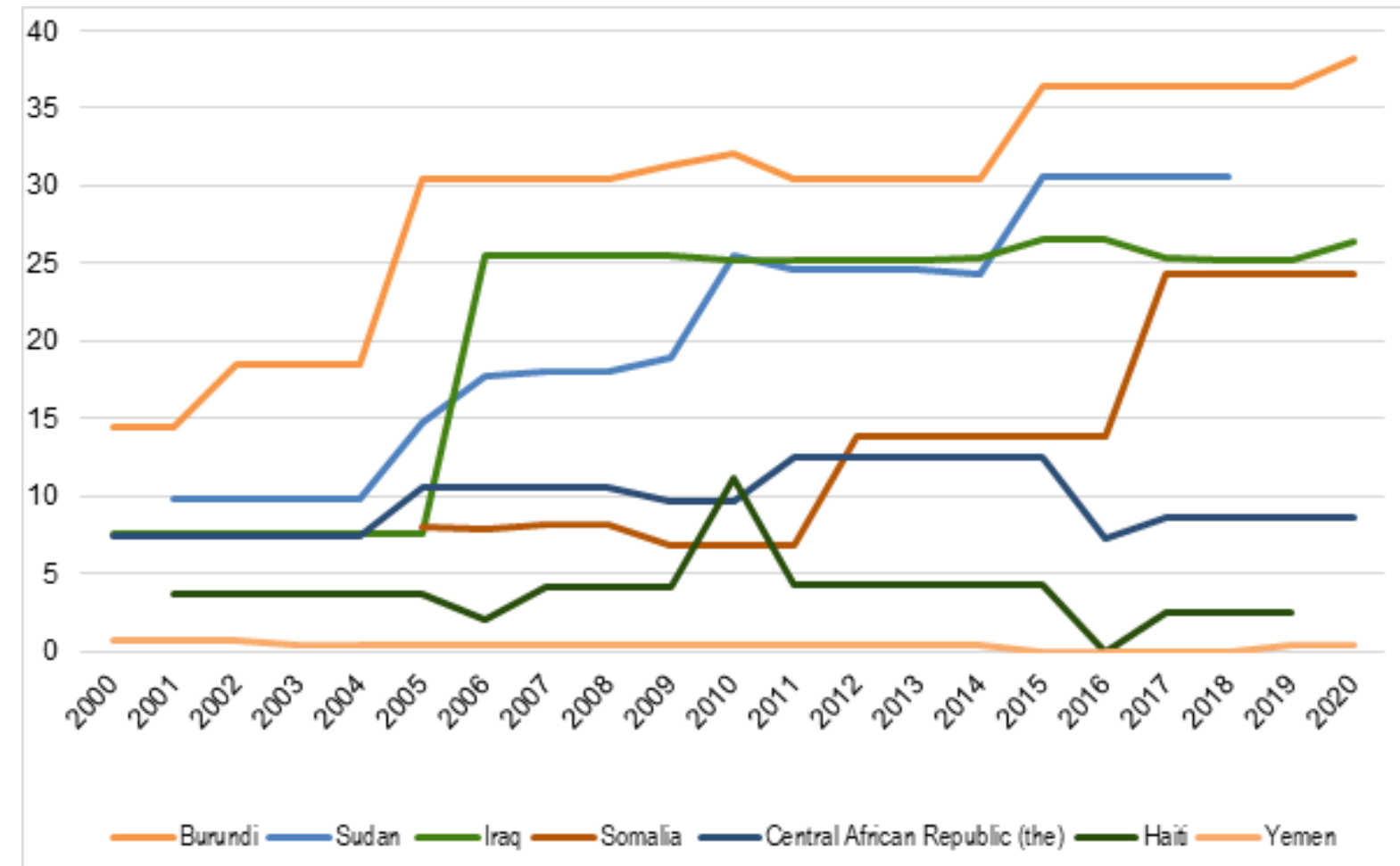

Note: Where trend lines are interrupted due to no value (parliament not being active, see Iraq, CAR), the previous percentage of female representation in parliaments when active is featured to highlight the trend and maintain a continuous line.

Source: Inter-Parliamentary Union (IPU).

Some of the main leaps in women's parliamentary representation observed in individual fragile contexts occurred during key moments that can be part of experiences of/transitions from conflict and fragility, such as peace negotiations, political transitions or constitution-making processes. These can provide openings to integrate quotas into foundational agreements - opportunities, which may not arise in more stable contexts. In Burundi, for example, a 30\% quota was agreed as part of the new constitution, which was adopted in 2005 following - and inspired by - the Arusha Peace Accord ending a decade of civil war and instability. In Iraq, a $25 \%$ quota was enshrined in the 2005 constitution agreed as part of the political transition. However, concerted action is needed to use such openings for the promotion of women's political participation. For donors, this implies adopting politically-informed approaches that recognise interlinkages between gender inequalities and fragility, including the rapid social and political transformations that often takes place in these contexts, and effectively support women as active agents within these change processes (OECD, 2020[3]).

Somalia finds itself at a critical juncture in determining whether such opportunities will be seized in its transition to advance women's political participation - or if existing achievements may be lost (Yasin, $\left.2019_{[25]}\right)$. A $25 \%$ quota was included in a political agreement governing its 2016 elections, the second round of elections since the establishment of the Federal Government. Efforts to enshrine a quota in the country's ongoing constitutional review and 2021 elections are continuing. In 2019, 350 women from across Somalia and the diaspora came together in Mogadishu to develop shared demands for their rights in the transition (the Somali Women's Charter), which included the call for a $50 \%$ constitutional quota for women in all public institutions. In a recent survey of 10300 women across the country, the majority of 
respondents $(92 \%)$ noted that they would like an opportunity to participate in decision making. Significantly, a vast majority of respondents $(86.6 \%)$ noted that it would be easier to access a decision maker if that person was a woman (Somalia, 2020[26]), pointing to the significance of women's representation in increasing the responsiveness of public institutions to the risks and concerns faced by women and girls.

While increased women's representation in parliament is a step into the right direction, it does not necessarily mean that this leads to women having an actual say in the political process or to enhanced women's empowerment. For example, OECD analysis shows that when comparing trends in women's political participation and women's empowerment in least developed countries, progress on empowerment is slower than progress on participation (OECD, 2018[27]).

\section{There are considerable opportunities to address fragility by promoting women's equal participation in the economy}

In 2015 the McKinsey Global Institute estimated that women participating in the economy identically to men could add up to USD 28 trillion, or 26\%, to annual global GDP by 2025 (2015) - then roughly the size of the US and Chinese economies combined. In a less demanding scenario, where countries matched the rate of improvement in the best-performing country in their region, enhancing women's participation in the economy would still add USD 12 trillion in annual 2025 GDP (McKinsey Global Institute, 2015[11]). McKinsey's updated estimates indicate that if policy makers would take action on gender equality now to address the negative impact of COVID-19 on gender equality, this could lead to USD 13 trillion of incremental GDP in 2030, an 11 percent increase relative to the do-nothing scenario (McKinsey Global Institute, 2020[28]).

There are considerable gaps in the extent to which such opportunities are used in fragile contexts. The Middle East and North Africa (MENA) region is among those that could experience the highest boost in GDP by promoting women's economic participation. Here, the Institute estimated that the "full potential" scenario could increase annual GDP in 2025 by $47 \%$ (USD 2.7 trillion) and the "best in region scenario" by $11 \%(0.6 \%)$. The main driver of this GDP growth ( $85 \%$ in the full potential scenario) would come from increasing women's labour force participation. Within the region, the ratio of female to male labour force participation is lower in the extremely fragile contexts, including Iraq (15.9\%), Syrian Arab Republic (19.3\%) and Yemen $(8.1 \%)$ than in any other country. What is more, as opposed to other countries in the region, these extremely fragile contexts have also experienced significant declines in the ratio of female to male labour force participation at different periods in the past 20 years, leading to an average decline by $23.3 \%$ since 2000 and by $18.7 \%$ since 2010. This trend is most extreme in Yemen, where the ratio of female to male labour force participation has consistently declined, dropping from $28.6 \%$ in 2000 and $14.6 \%$ in 2010 to $8.1 \%$ in 2020 (see Figure 3.3).

Moreover, Iraq, Syria and Yemen have legislation in place that curtails women's access to opportunities in the labour market in different ways (World Bank, 2020[29]). For example, the legislation of Yemen and Iraq obliges a married woman to obey her husband, including in issues related to her access and engagement in the labour force. In Syria and Yemen, a woman cannot get a job in the same way as a man. ${ }^{6}$ The legislation of Syria, Yemen and Iraq do not prohibit discrimination in access to credit based on gender and in the three countries, sons and daughters do not have equal rights to inherit assets from their parents, which significantly restricts their economic empowerment and the opportunity to start a business. Social norms that are not in favour of women's economic empowerment also come out strongly in these countries. In Yemen and Iraq, almost half of the population ( $49 \%$ and $46 \%$ respectively) disagrees with the statement that "It is perfectly acceptable for any woman in your family to have a paid job outside the home"7 (SIGI, $\left.2021_{[30]}\right)$. 
Figure 3.3. Ratio of female to male labour force participation in extremely fragile contexts in the Middle East and North Africa region

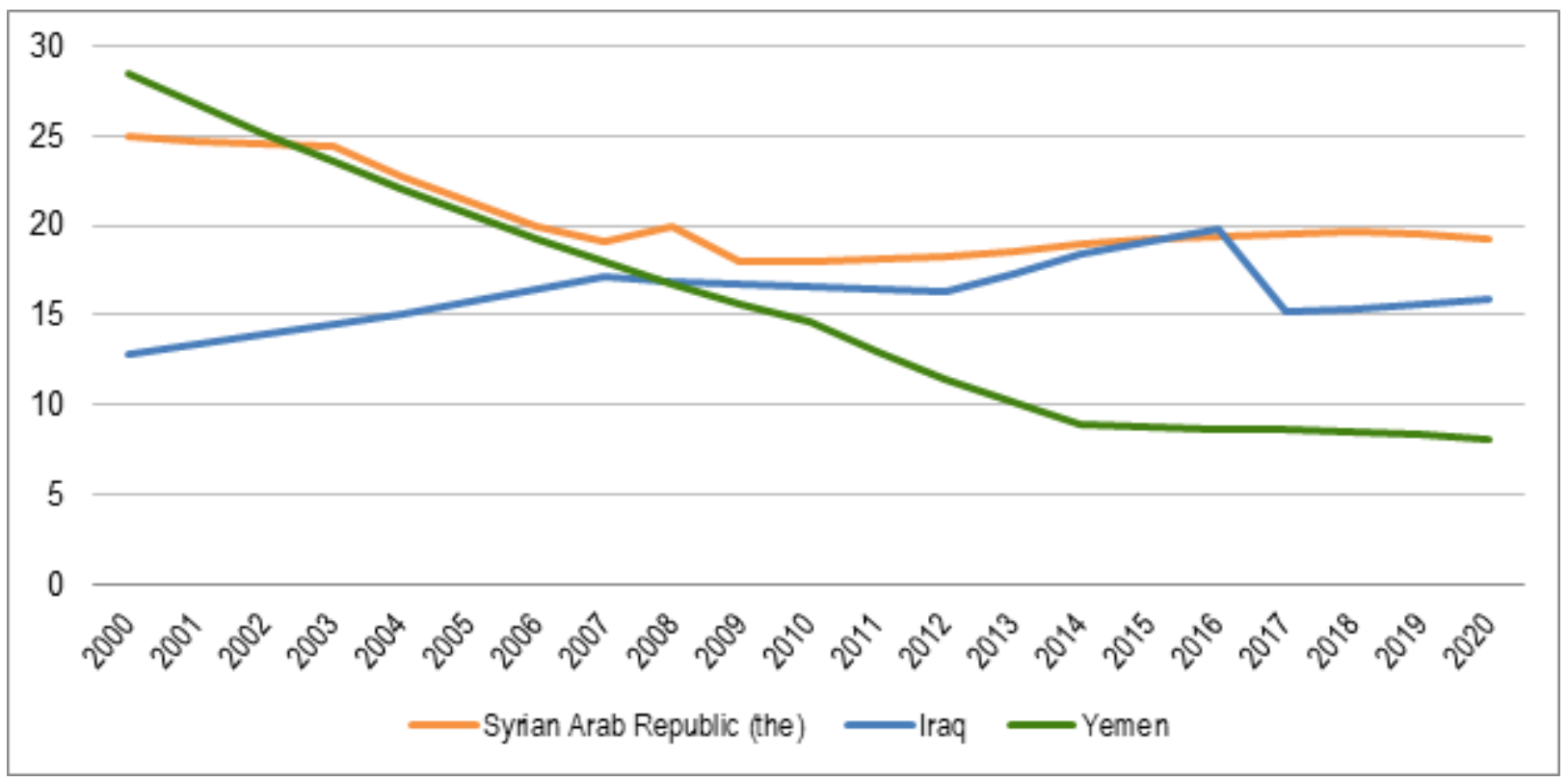

Source: International Labour Organization (ILO), ILOSTAT (database): https:/lilostat.ilo.org/.

Sub-Saharan Africa could gain up to USD 27 trillion in the "full potential" scenario of closing gender-related gaps $(0.7 \%$ of GDP) and USD 12 trillion $(0.3 \%)$ in the "best in region" scenario. Women's labour force participation rates are relatively high in Sub-Saharan Africa. Outliers with the lowest ratios of female to male labour force participation in the region are two of the extremely fragile contexts: Somalia $(29.5 \%)$ and Sudan $(42.7 \%)$. Given relatively high labour force participation in the region, a main driver of the potential gender-related GDP growth in Sub-Saharan Africa would be changing the sector mix of female employment, and engaging women in higher productivity sectors. In the region, fragile contexts employ more women in agriculture, a relatively low productivity sector, than other countries, both in terms of the share of female employment and in relation to male employment. The percentage of female employment in agriculture out of total female employment and the ratio of female to male shares of employment in agriculture are even higher in the extremely fragile contexts than in other fragile contexts. What is more, these gaps have been closing more over time in other developing countries than in fragile contexts, and especially extremely fragile contexts, in Sub-Saharan Africa (see Figure 3.4). 
Figure 3.4. The ratio of female to male shares of employment in agriculture in different contexts in Sub-Saharan Africa

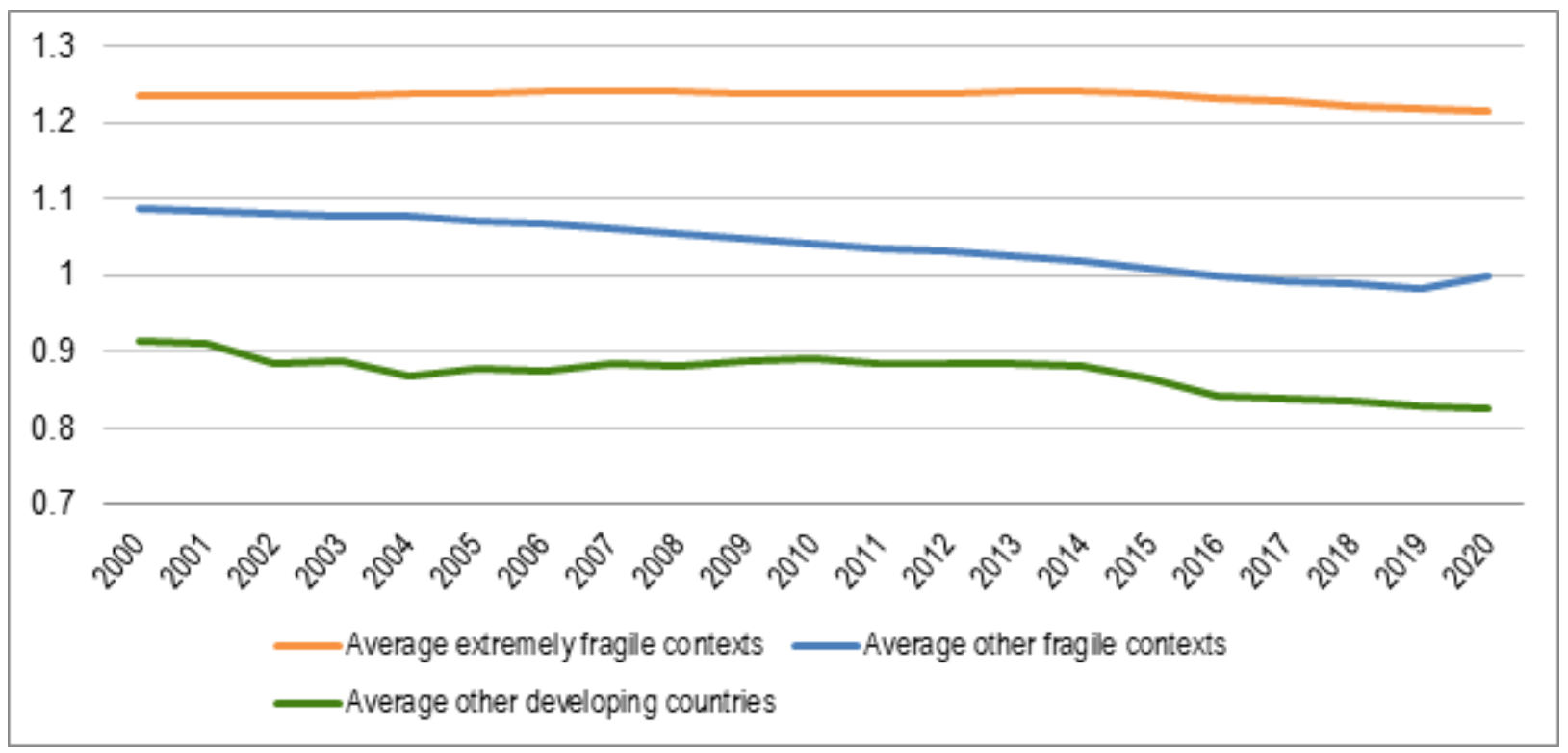

Note: The ratio is calculated by dividing female employment in agriculture (\% of female employment) by male employment in agriculture (\% of male employment). A value greater than one indicates that the share of female employment that is in agriculture is greater than the share of male employment that is in agriculture.

Source: World Bank Data: https://data.worldbank.orgl; and ILO, ILOSTAT (database): https://ilostat.ilo.org/.

South Asia is also among the regions that could gain the most by closing gaps in women's participation in the economy. Even excluding India, a "full potential" scenario could add an estimated 48\% (USD 0.4 trillion) to global GDP, while the "best in region" scenario could contribute a potential 11\% (USD 0.1 trillion). In South Asia (excluding India), $67 \%$ of this increase would be driven by increasing women's labour force participation. Other than India, fragile contexts in the region have the lowest ratios of female to male labour force participation rates. Currently these are at $29.2 \%$ in Afghanistan, $27.1 \%$ in Pakistan and $44.8 \%$ in Bangladesh. However, these countries have seen considerable progress in women's labour force participation over time, more so than other countries in the region (see Figure 3.4). In Afghanistan, the ratio of female to male labour force participation rates has increased by more than half (53\%) since 2010. In Bangladesh, the ratio has consistently risen, by a total of $43 \%$ since 2000 . In Pakistan, it expanded considerably in the earlier years of the new millennium, from $19 \%$ in 2000 to $27 \%$ in 2010 (see Figure 3.5). 
Figure 3.5. Ratio of female to male labour force participation over time in different contexts in South Asia

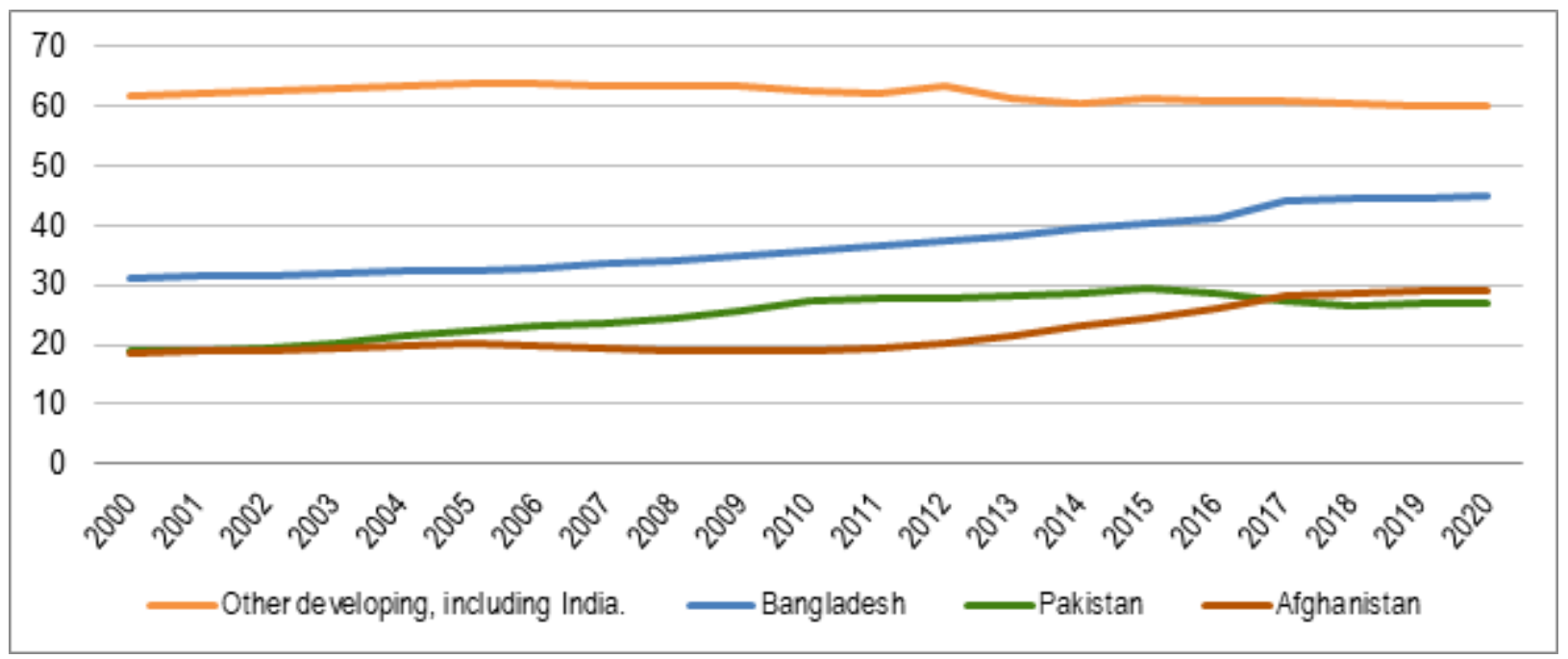

Source: ILO, ILOSTAT (database): https://ilostat.ilo.org/

However, beyond labour force participation, another $25 \%$ of the expected GDP growth in South Asia (excluding India) would be driven by closing gaps in the sector mix of employment between men and women. In addition to lower ratios of labour force participation, the fragile contexts are also marked by a higher ratio of female to male shares of employment in agriculture, a relatively low productivity sector. What is more, this ratio has increased further in the fragile contexts in recent years, while it has declined slightly in other developing countries in the region (see Figure 3.6).

Figure 3.6. Ratio of female to male shares of employment in agriculture in different contexts in South Asia.

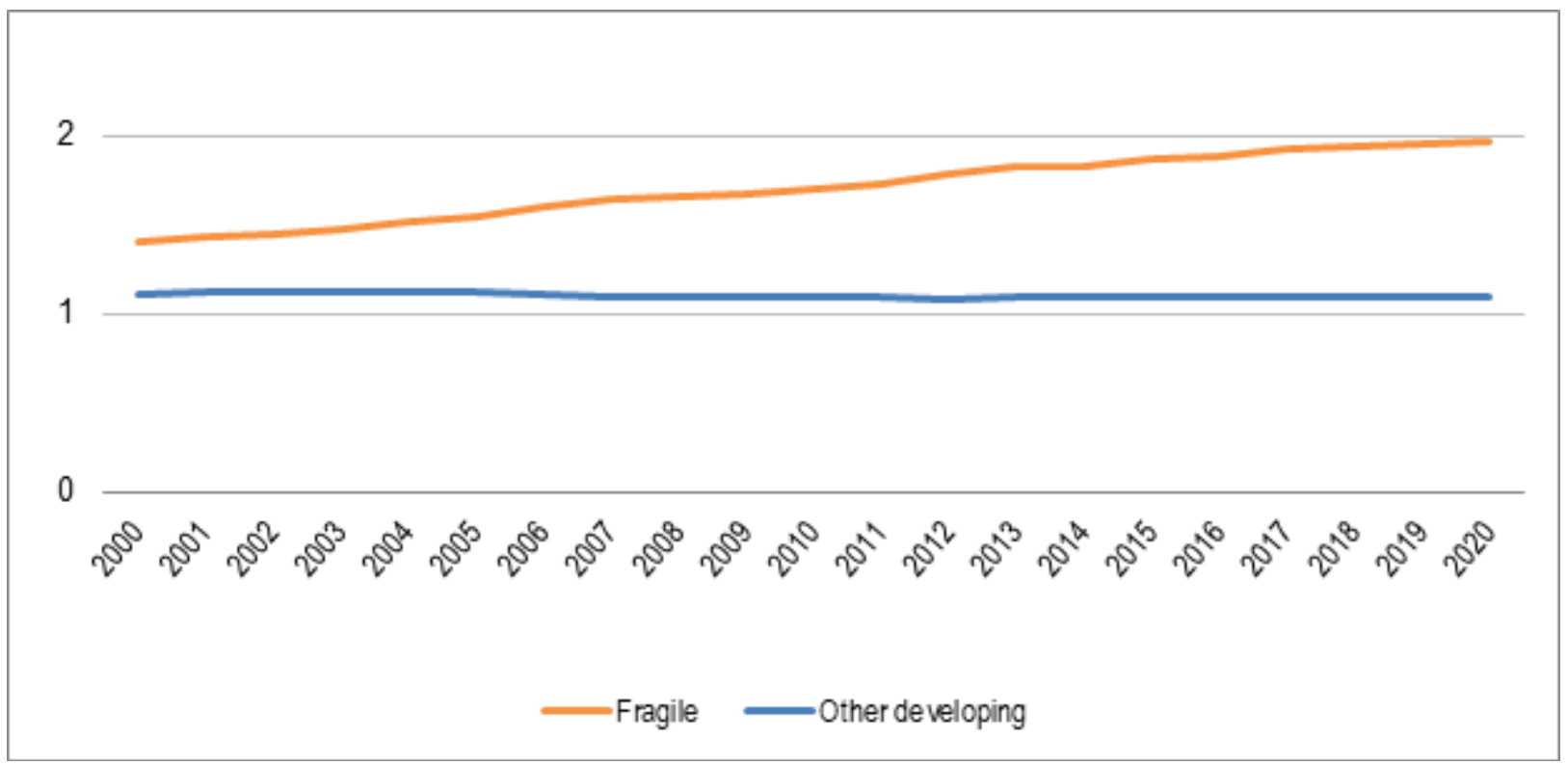

Source: World Bank Data: $\underline{\text { htps://data.worldbank.orgl; and ILO, ILOSTAT (database): https://ilostat.ilo.org/. }}$ 
These trends suggest that there are considerable opportunities to address fragility by promoting women's equal participation in the economy. However, the economic and productive sectors ${ }^{8}$ have received a comparatively low, and stagnant, share of aid targeted at gender equality in fragile contexts. In 2018/2019 only USD 206 million (2\%) out of the total USD 11.0 billion committed to the sectors in fragile contexts was dedicated to gender equality as a principal objective (OECD, 2020[31]). The UN has suggested that a minimum of $30 \%$ of funding on economic recovery programmes in conflict and post-conflict situations should be specifically dedicated to gender equality (UNSC, 2011 [32]).

In addition to the economic benefits, there are many other advantages to enhancing women's economic empowerment. For example, there is a strong correlation between gender equality and human development (UNSG, 2016 ${ }_{[33]}$ ). Evidence indicates that if women have an income, they are most likely to spend it on food, health and children's needs (World Bank and FAO, 2009[34]). Moreover, data shows the linkages between higher levels of gender equality and lower child mortality, especially in fragile contexts (Marphatia et al., 2016[35]). FAO states that "if women farmers had the same access to resources as men, the number of hungry people in the world could be reduced by up to 150 million" (FAO, 2016[36]).

\section{Data suggests that fragile contexts may be marked by particularly permissive attitudes towards male violence}

Prior to the pandemic, almost $27 \%$ women and girls (aged between 15 and 49 years) who had ever been in a relationship had experienced intimate partner violence (IPV) (WHO, 2021 [4] ). The highest prevalence of IPV is found in the least developed countries (37\%) (UNGA, 2020[37]; WHO, 2021 [38]). These global figures highlight the growing urgency to address this worrying trend, especially in light of COVID-19.

In 26 of the 57 fragile contexts, home to 322 million women in 2020, there is no legislation in place that specifically addresses domestic violence. Only 3 out of 13 extremely fragile contexts have this type of legislation in place. The absence of legislation on domestic violence also reflects the wider attitudes related to violence against women and girls. Existing surveys suggest that attitudes towards male violence against their partners may be particularly permissive in fragile contexts. These are included in the SIGI physical integrity index as one of the sub-indicators on violence against women. This indicator suggests that the social acceptability of domestic violence may on average be considerably higher in fragile contexts, and especially in extremely fragile contexts, than in other developing countries. In extremely fragile contexts, on average, almost two thirds $(65.5 \%)$ of women aged 15-49 reportedly consider a husband to be justified in hitting or beating his wife for at least one of several specific reasons, including if his wife burns the food, argues with him, goes out without telling him, neglects the children or refuses sexual relations. In other fragile contexts, on average, $43.5 \%$ of women $15-49$ considered such violence to be acceptable in dedicated surveys, compared to an average of $23.3 \%$ in other developing contexts (see Figure 3.7 ). 
Figure 3.7. Percentage of women aged 15-49 who consider a husband to be justified in hitting or beating his wife under at least one of several specific reasons

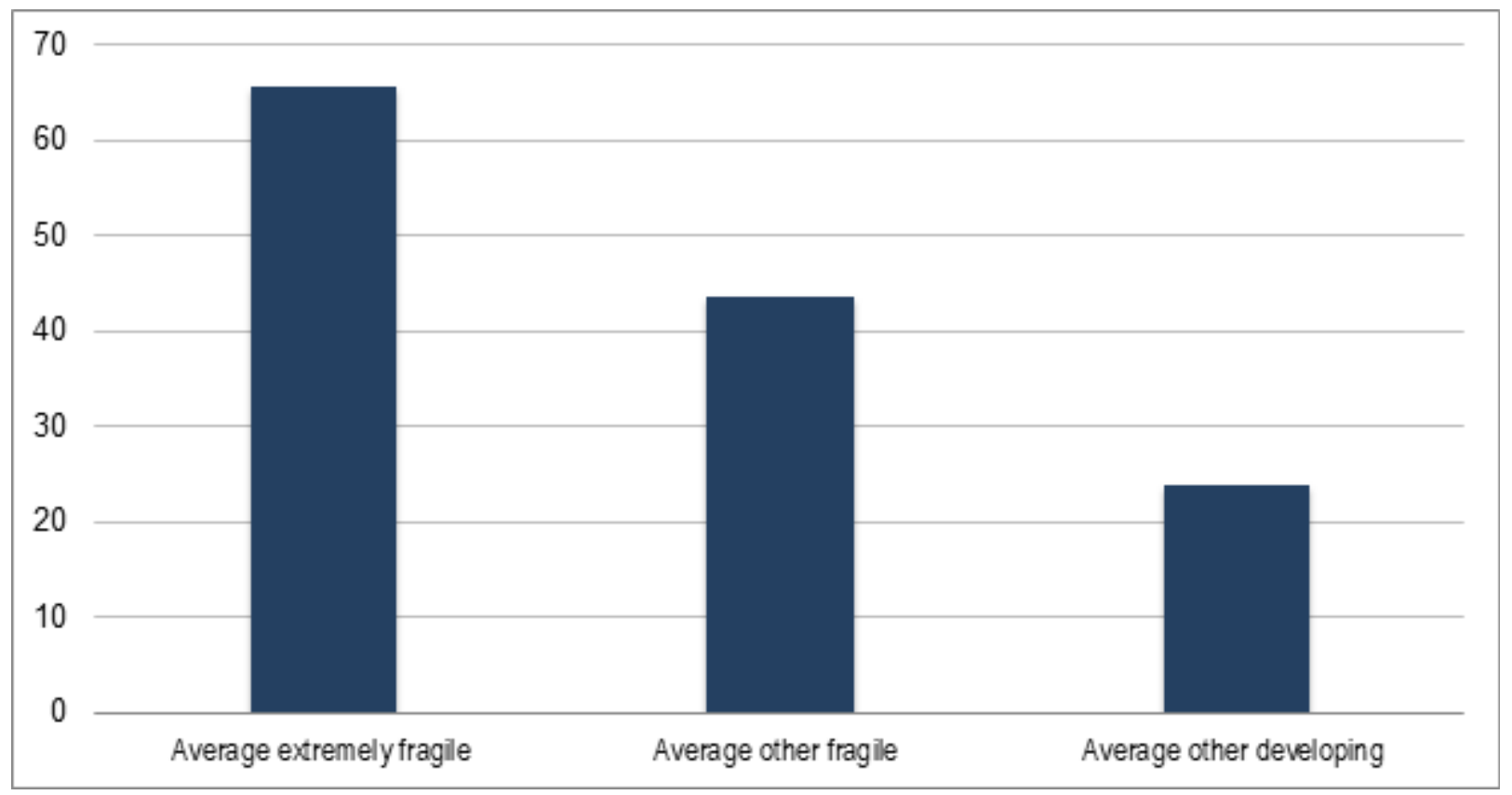

Source: OECD SIGI (2021 $\left.{ }_{[30]}\right)$, Social Institutions and Gender Index Database, https://stats.oecd.org/Index.aspx?DataSetCode=GIDDB2019 (accessed on 10 February 2021).

Existing research suggests that such attitudes may well be connected to wider societal violence. Societal expectations accepting - or celebrating - men for acting with dominance, aggression and violence are often drawn upon by armed groups to recruit men for violence. Military training tends to further engrain these perceptions (Wright, 2014[16]). Engaging with male gender roles can therefore make important contributions to preventing violence both in the public and the private spheres. Recent OECD research has outlined key lessons, emerging best practices and recommendations in this regard (OECD, 2019[15]).

\section{Gender inequality and the gender aspects of fragility are not one issue but many}

While most of the 57 fragile contexts are marked by severe gender inequalities, the indicators suggest that the nature of these inequalities varies significantly from one fragile context to the next. In addition to the variation in women's parliamentary representation highlighted above, there is great variation across different fragile contexts in other indicators captured in the framework, including women's labour force participation ratios, the Gender Inequality Index, SIGI physical integrity index, as well as the sub-indicators that are aggregated into these indices (such as maternal mortality, adolescent fertility, the ratio of women with at least some secondary education, laws, attitudes and practices relating to domestic violence, Female Genital Mutilation (FGM), sexual and reproductive health and rights).

Significantly, while there will be associations between some indicators, progress on different gender inequalities/gender dimensions of fragility does not necessarily go together in the same context. That is, countries that do better in one area of gender equality do not necessarily do better in others. For example, according to sub-indicators of the SIGI physical integrity index, most fragile contexts in Latin America are marked by relatively strong laws on violence against women compared to other fragile settings - but maintain especially restrictive laws on reproductive autonomy (see Figure 3.8). Recent statistical research affirms that progress on these policies is associated with distinct factors. In particular, the potential for laws 
on reproductive autonomy is likely to be shaped by the significance of religious institutions in politics. Laws on domestic violence are more independent of this factor and tend to be strongly related to the strength of autonomous women's mobilisation (Htun and Weldon, 2018[7]).

\section{Figure 3.8. Strength of laws on violence against women and reproductive autonomy in fragile contexts in Latin America}

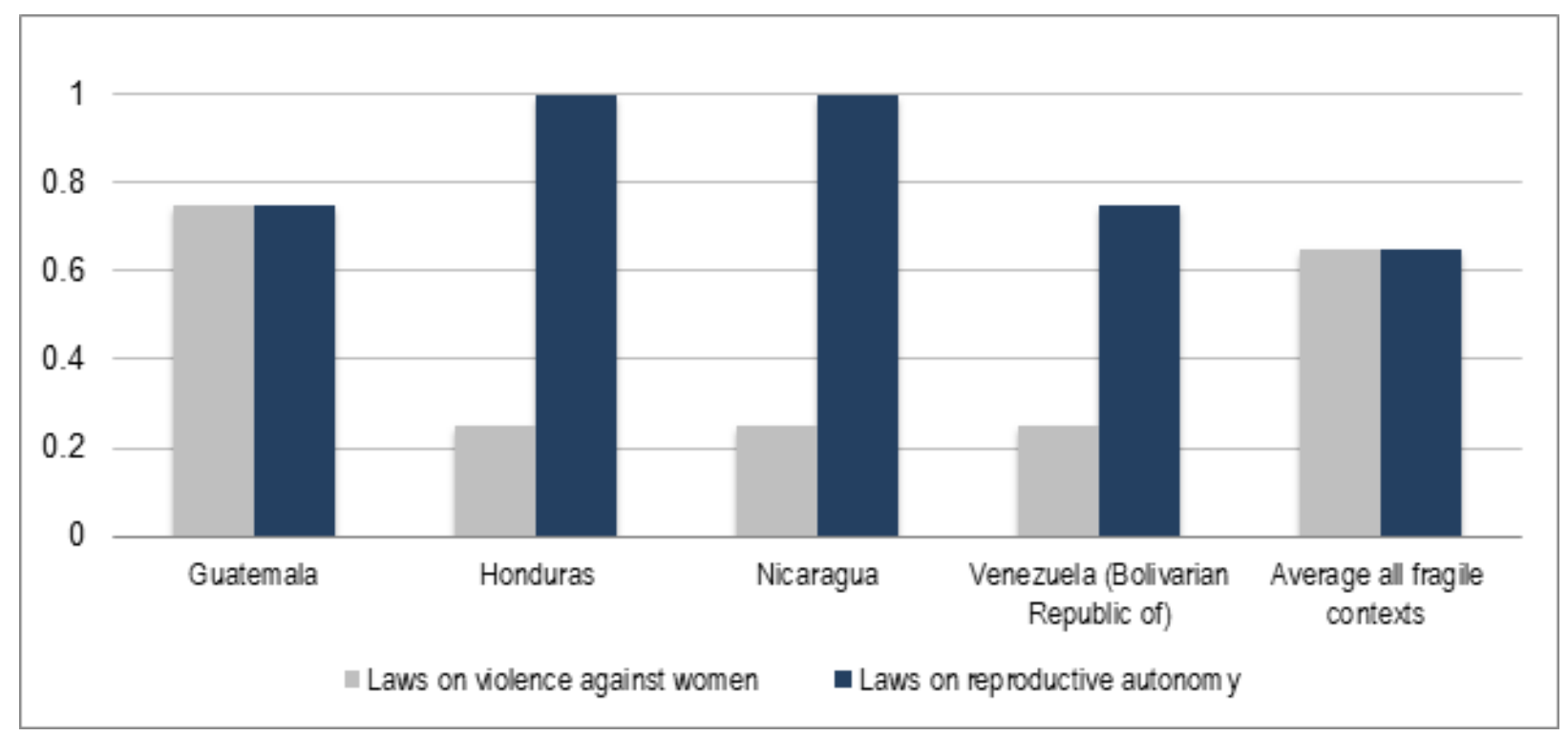

Note: These sub-indicators of the Social Institutions and Gender Index assess the nature of laws on reproductive autonomy (whether the legal framework protects women's reproductive health and rights) and violence against women (whether the legal framework protests women from violence including intimate partner violence rape and sexual harassment, without legal exceptions and in a comprehensive approach). Scores range from 0 (strong legal protections/a low level of legal discrimination) to 1 (a lack of legal protections/high level of legal discrimination). Source: OECD SIGI (2021 [30]), Social Institutions and Gender Index Database, https://stats.oecd.org/Index.aspx?DataSetCode=GIDDB2019 (accessed on 10 February 2021).

Similarly, women's participation in the economy, on the one hand, and in politics, on the other, often follow distinct logics and trajectories. According to OECD, "trends in women's political participation and women's empowerment in the least developed countries show that progress on empowerment is slower than progress on participation" (OECD, 2018[27]). In fragile contexts in South Asia, for example, women's labour force participation ratios lie well below the average ratio of all other fragile contexts, while women's representation in parliaments matches - or exceeds - the average for all other fragile contexts (see Figure 3.9). Among fragile contexts in the MENA region, Iraq and Yemen have the lowest ratios of female labour force participation (15.9\% and $8.09 \%$, respectively). However, Iraq has the highest level of women in parliament among these countries $(26.4 \%)$ while Yemen has the lowest $(0.3 \%)$. 
Figure 3.9. Ratio of female to male labour force participation rate and proportion of seats held by women in national parliaments in fragile contexts in South Asia (2020)

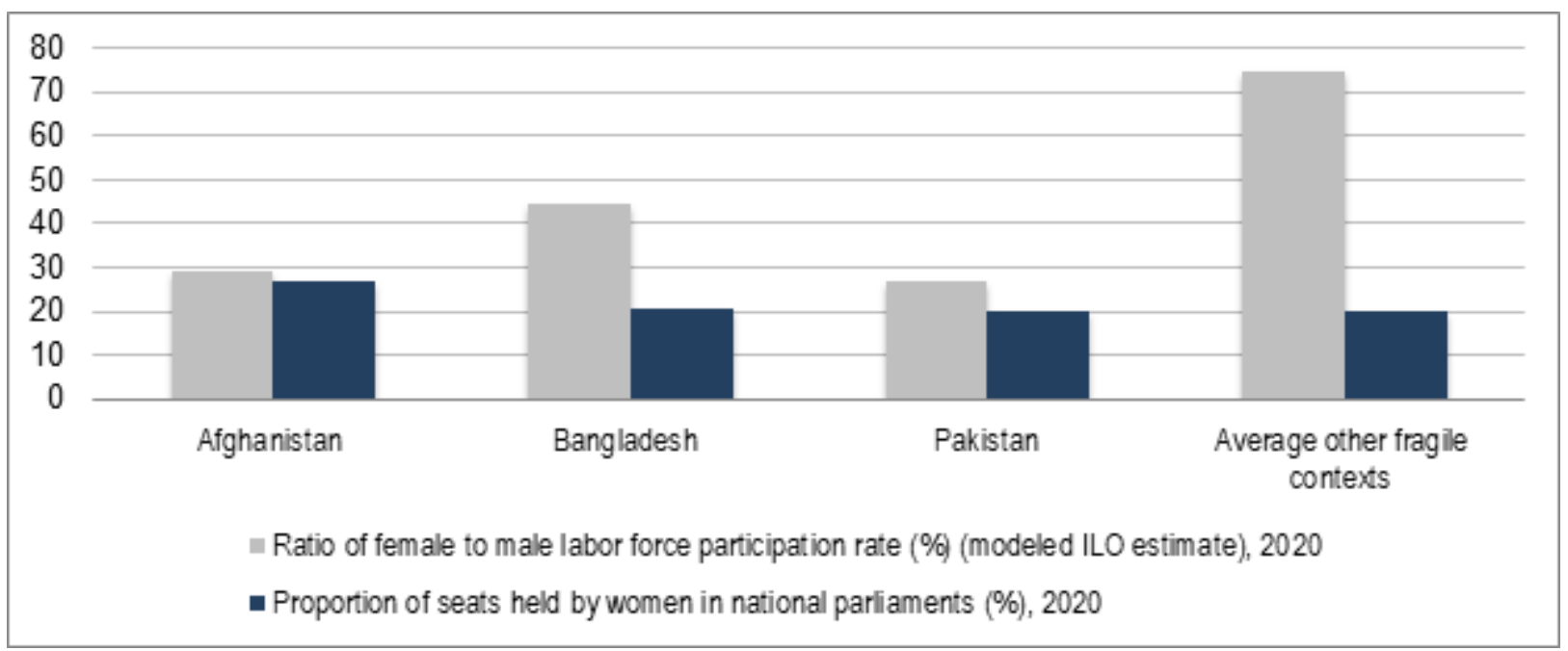

Note: the table features most recent values available at the time of the research, which are 2019 for Haiti and 2018 for Sudan in terms of political representation and 2020 for all other values.

Source: ILO, ILOSTAT (database): https://lilostat.ilo.org/; and Inter-Parliamentary Union (IPU) Parline (database): https://data.ipu.org/.

These trends add weight to a key conclusion of recent statistical research in a different selection of contexts (Htun and Weldon, 2018[7]): Gender equality is not one issue, but many issues - and so are the gender dimensions of fragility. This confirms the need to include a diversity of components and indicators of gender equality in an assessment of fragility - the reality of gender dimensions of fragility cannot be captured through a single measure or a limited number of indicators.

\section{The scale of gender inequalities seen in many fragile contexts is rarely matched by dedicated resources}

Official development assistance (ODA) for gender equality and women's empowerment is steadily increasing with OECD DAC members contributing USD 53 billion (45\% of bilateral aid) either integrating or dedicated to gender equality on average per year in 2018-19 (OECD, 2021 [39]). In the 57 countries and territories that are considered as fragile contexts by the OECD, ODA is the second most important source of external finance after remittances. OECD data shows that DAC bilateral aid to gender equality and women's empowerment in fragile contexts has been steadily rising over the past ten years, reaching USD 20.7 billion dollars in 2018-19 (on average) ${ }^{9}$ However, only USD 2.3 billion in that period was dedicated to gender equality as a principal objective of the programme, corresponding to $5.6 \%$ of bilateral aid to fragile contexts ${ }^{10}$.

While the nature of the challenges varies between contexts, fragile settings - and especially some of the most fragile contexts - are certainly marked by extreme gender inequalities.

Among all fragile contexts, Yemen $(0,834)$, Chad $(0,70)$ and Central African Republic $(0,682)$ have the highest Gender Inequality Index (GII), indicating extremely high disparities between men and women and corresponding losses to human development. These include the lowest ratio of female to male labour force participation among all fragile contexts in Yemen (8.1\%), low rates of female parliamentary representation in all three countries $(0.33 \%$, the second lowest among all fragile contexts in Yemen, $8.6 \%$ in Central African Republic and 15.4\% in Chad), high maternal mortality (1 140 per 100000 live births in Chad, 829 in Central African Republic and 164 in Yemen), high adolescent fertility as well as great 
disparities in education. As a result of these trends, their Gender Inequality Indices are the highest globally, with Yemen ranking at the bottom of global GIl rankings (162/162), closely followed by Chad (160/162) and Central African Republic (159/162).

However, among these three countries in 2018-19, only Yemen featured as a top ten fragile recipient of aid to gender equality, mostly due to a 184\% increase in such ODA from 2017 (USD 432 million) to 2019 (USD 1.2 billion); previously, Yemen had received USD 242 million in such ODA every year from 2010 to 2017, well below the DAC average. Meanwhile, Chad (USD 213 million) and Central African Republic (USD 176 million) ranked $28^{\text {th }}$ and $33^{\text {rd }}$, respectively, as recipients of ODA to gender equality among fragile contexts, receiving significantly below the average volume (USD 364 million) of such ODA to fragile contexts in 2018-19. Figure 3.10 further cements that ODA to gender equality is not well correlated with gender inequality scores in fragile contexts.

Figure 3.10. The relationship between official development assistance to gender equality and women's empowerment and the Gender Inequality Index in fragile contexts

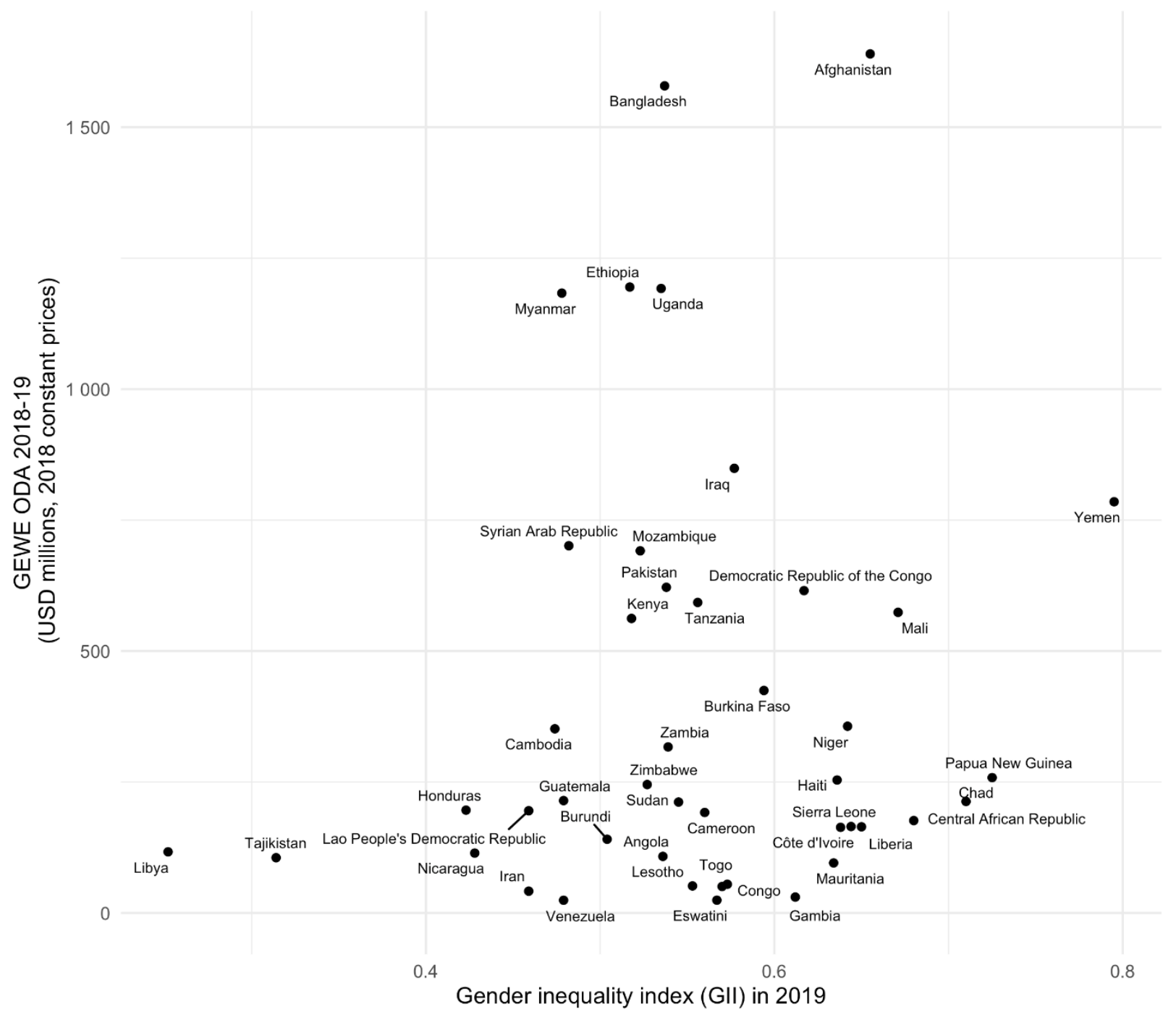

Note: Gender inequality index scores were missing for 13 fragile contexts. Please note that "GEWE" stands for "Gender equality and women's empowerment".

Source: OECD DAC Creditor Reporting System: https://stats.oecd.org/Index.aspx?ThemeTreeld=3; and UNDP Human Development Report office: http://hdr.undp.org/en/data. 


\section{Global indicators must be complemented by careful contextual analysis in assessing gender relations as a part of fragility}

While the gender-related statistics collected as part of the fragility framework can offer a useful first glance at complex situations, it is important to complement global profiles with more detailed contextual analysis. This is, of course, generally a good practice and complementing statistical research with contextual expertise and qualitative assessments is part of the OECD's approach to measuring fragility.

However, a number of challenges with gender-related data amplify the need for closer, contextual, qualitative analysis. First, some of the global indicators captured in the framework can of course mean different things depending on the wider context. For example, many fragile contexts are not full democracies (Economist Intelligence Unit, 2020[40]). Regardless, women's representation in parliaments can also have significant effects in countries that are not full democracies. Additionally, women's representation in parliament can have diverse effects depending on wider regime characteristics (including whether parliament has any power at all). However, possible effects require careful contextual analysis and programming in order to address pre-existing normative social frameworks (OECD, 2019 [15]; OECD, 2020[3]). Importantly, the number of women in parliament alone is not indicative of positive societal change and women's political empowerment (Cowper-Coles, 2020[41]). What is indicative in determining the full effect of societal change is how women are included in the decision-making processes.

What is more, global indicators may not be available for key elements of women's realities/gender aspects of fragility in particular. For example, global indicators for women's labour force participation are not likely to fully capture women's contributions through the informal sector, part-time work, work in or near their homes (and unpaid work). Somalia, for example, has a relatively low ratio for female labour force participation. However, local estimates suggest that women provide around $70 \%$ of household income on average, playing a key role in sustaining families, communities and the economy. (Somalia, 2020[26]) The global indicators alone do not capture this reality. The indicators from Afghanistan suggest serious challenges, but also great progress. However, they cannot capture an underlying source of risk/fragility for women: the nature of the political settlement. Generally, gender-related data tends to be particularly scarce, especially in fragile and conflict-affected contexts. Finally, some of the issues addressed in the gender-related data, including violence against women, can be especially sensitive. Careful interpretation is therefore required when assessing associated statistics/survey results, including around the prevalence of domestic and sexual violence. Given these specific challenges, developing further qualitative analysis of gender-related trends in fragile contexts may be a priority for future States of Fragility reports as well as the States of Fragility platform.

\section{Beyond adding individual variables, the gender aspects of fragility expand perspectives on fragility}

As the 2020 States of Fragility report has highlighted, fragility is inherently complex. It tends to manifest as a complex web of interdependent challenges, marked by interactions between formal and informal networks, institutions and economies and diverse national and international stakeholders, each with their own agendas and priorities (OECD, 2020 [1] $)$. Attention to the gender aspects of fragility not only suggest a number of additional variables for consideration in our analysis of this system - it also expands and deepens our overall perspective on fragility. This is true in at least two ways. First, the gender aspects of fragility draw increased attention to the significance of social norms in the analysis of fragility. Societal expectations for male and female behaviour, gender norms, are root causes of the gender aspects of fragility discussed throughout this chapter. For example, research has consistently found that discriminatory social norms are structural drivers of violence against women (WHO, 2021 [4]). As highlighted above, the same discriminatory attitudes can also drive wider forms of societal violence, including by 
facilitating recruitment of men into armed groups. In a range of fragile contexts, discriminatory legal frameworks and restrictive social norms continue to hold back women's participation in the economy and women's economic empowerment more broadly. This is a missed opportunity for working towards more sustainable economic growth and harnessing the social benefits of women's economic empowerment in these contexts.

By highlighting these connections, the gender aspects of fragility also draw attention to a second aspect of fragility: the significance of the private sphere - and its interconnectedness with the public sphere - in understanding fragility. The societal norms that drive violence against women in the household can also drive violence in the streets. Times of crisis not only exacerbate public violence, but also violence against women and children in the home (True, 2012[42]). Expectations for women and girls' behaviour in the private sphere, including caregiving responsibilities, often hold back their education and labour force participation, and therefore economic growth. They also reduce women's time and aspirations to participate in political life. In these ways, the gender aspects of fragility raise new questions and add further layers of complexity to the analysis of fragility.

\section{COVID-19 and gender aspects of fragility}

The data featured in this chapter reflect the gender indicators of fragility before the outbreak of the COVID-19 pandemic. Reports from around the world make abundantly clear that the pandemic has exacerbated - and will likely continue to aggravate - many of the trends observed above. Data from UN Women reports that the poverty rate for women is projected to increase by over $9 \%$ due to the impact of the pandemic, with the largest increases in Central and Southern Asia and sub-Saharan Africa (where 87 percent of the world's extreme poor live) (UN Women, $2020_{[43]}$ ). In what has been termed the "shadow pandemic" (Mlambo-Ngcuka, 2020[44]), COVID-19 has also exacerbated levels of violence against women in many contexts. Given existing high levels of domestic violence in many fragile settings and the relatively low availability of services, women and girls in these contexts are likely to be especially vulnerable. For example, in Nigeria the number of reported rape cases increased significantly since the beginning of the pandemic (Radi, 2020[45]). Findings from a study in rural Bangladesh indicated that over $50 \%$ of women who experienced emotional or physical violence before the pandemic, reported an increase since the lockdown (Hamadani et al., 2020[46]). A community study in Uganda shows a perceived increase in domestic violence, mostly driven by men's loss of employment due to the pandemic (Parkes et al., $2020_{[47]}$ ). In Ethiopia, heightened risk of child marriages was reported, due to school closures and the lack of control from government officials following lockdown (Jones et al., 2020[48]).

Women and girls also shoulder disproportionate caregiving responsibilities and are more likely to be pulled out of school and the labour force as a result. Women's existing over-representation in part-time and, especially in fragile contexts, informal employment, have made them more vulnerable to the fallout of the pandemic. For example, UN Women estimates indicate that during the first month of the pandemic, informal workers in Sub-Saharan Africa lost on average $81 \%$ of their income (UN Women, 2020[43]).

At the same time, the pandemic has underlined the significance of women's diverse contributions in making societies resilient to such shocks, especially in areas where support from the state is limited. Globally, they make up $70 \%$ of the health force battling the pandemic and $60 \%$ in fragile contexts. Women have also disproportionately cared for the sick at home, particularly in areas with limited availability of health services. Women's income can increase the resilience of households in the face of job loss by individual household members. The pandemic has also shed further light on the roles women often take on in human capital development, as they stepped in to provide for children and their education in the wake of school closures across the globe. ${ }^{11}$

Although women and girls in fragile settings are likely to experience these and other gender-related challenges to an even greater extent during and after the COVID-19 pandemic, data from the UN Women 
COVID-19 Global Gender Response Tracker (UN Women, n.d.[49]) suggests that, overall, fragile contexts have introduced fewer measures specifically targeting women's experiences of the pandemic in different areas than other developing contexts (see Figure 3.11). Based on publicly available information from UNDP and UN Women country offices, the tracker monitors policy measures enacted by governments around the world to address the pandemic and highlights responses that integrate a gender perspective. It includes national measures that directly address women's economic and social security, including unpaid care work, the labour market and violence against women. Among these areas, fragile and non-fragile developing contexts have been most active in developing response to gender-based violence, while responses to women's unpaid care burden have been particularly lacking.

\section{Figure 3.11. Average number of gender-sensitive COVID-19 response measures introduced by} fragile and other developing contexts in different areas

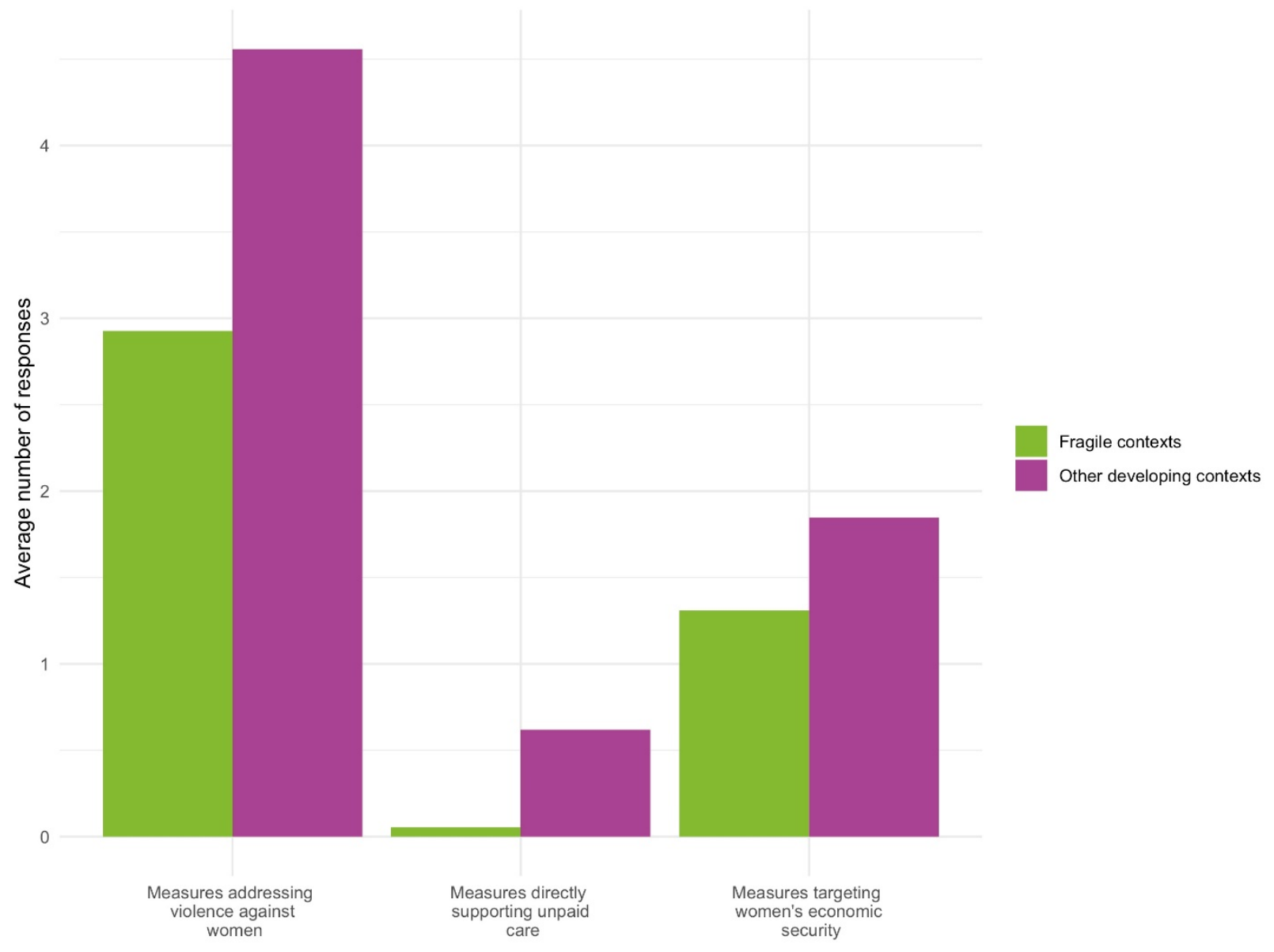

Note: Gender-sensitive measures that support women's economic security include: (a) social protection measures that target women or prioritise them as the main recipients of benefits; (b) labour market measures aimed at improving women's access to paid work and trainings; and (c) fiscal and economic measures that channel support to female-dominated sectors of the economy. Gender-sensitive measures that address unpaid care include: (a) social protection measures that support women and men with care responsibilities or improve services for populations with care needs; and (b) labour market measures that help female and male workers with care responsibilities to cope with the rising demand for unpaid care. For further details on methodology see: COVID-19 Global Gender Response Tracker, available at: https://data.undp.org/gendertracker/.

Source: UN Women (n.d.[49]), COVID-19 Global Gender Response Tracker. https://data.undp.org/gendertracker/ 
However, the scope and nature of gender-sensitive responses have certainly varied across different fragile contexts. In a number of fragile contexts, significant steps have been reported to address specific effects of the pandemic on women and girls. In the West Bank and Gaza, the cabinet issued 13 measures to protect victims and survivors of violence during the crisis. The government also set up a national fund to support daily wage earners and informal sector businesses. An estimated 9000 informal businesses have registered, and it is expected that 200000 families will be supported through this programme. Given that women tend to be disproportionately in the most vulnerable types of informal employment, this programme can help ensure they are included in the economic response to the pandemic. The United Nations Population Fund (UNFPA) has in turn increased efforts to maintain sexual and reproductive health services in conflict-affected contexts. In Syria, the UNFPA is co-ordinating with the Ministry of Health to sustain pre- and post-natal care, including by supporting the establishment of dedicated mobile clinics (OECD, 2020[50]).

Cambodia has been especially active in developing measures to (continue to) respond to violence against women during the pandemic. Amongst other steps, the Ministry of Women's Affairs, in collaboration with non-governmental organisations and development partners, has conducted awareness-raising with material combining COVID-19 and violence against women and girls (VAWG) messages, strengthened or updated reporting mechanisms, including by ensuring that staff at district level were equipped with smartphones and tablets to enable urgent communication with survivors during the pandemic, and taken action to research the effects of COVID-19 on gender-based violence (GBV) cases and demand for services (UN Women, n.d.[49]). In Myanmar, beneficiaries of the Maternal and Child Cash Transfer Program (which supports pregnant women and mothers of children under the age of two) were to receive a one-off cash payment in addition to the existing monthly payment. The total budget is USD 4.9 million, benefiting 241425 households (UN Women, n.d.[49]). In Honduras, the government, financed by the Central American Bank for Economic Integration, has launched a programme to strengthen micro-enterprises led by Honduran women. In particular, the programme is designed to provide women with access to low-interest financing, training in areas such as digital commerce and improve their access to national and international markets (UN Women, n.d.[49]).

The OECD has developed guidance on how to support gender-sensitive measures throughout COVID-19 response, recovery and prevention efforts in development co-operation. In this context, given the increased risks due to the implications of the pandemic, it highlights that the DAC Recommendation on Ending Sexual Exploitation, Abuse, and Harassment in Development Co-operation and Humanitarian Assistance is also more significant and relevant than ever (OECD DAC, 2019[51]). In view of the immense challenges faced by women and girls, the guidance calls on development partners to maintain, and wherever possible, increase commitments to development assistance and ensure that levels of aid focused on gender equality grow in the COVID-19 recovery phase (OECD, 2020[52]). 


\section{Conclusions}

Gender equality remains an integral part of understanding the complexity of fragility. Likewise, applying lessons learned on gender equality in fragile contexts can have far-reaching implications. Benefits can be seen in areas of women's political and economic empowerment and via opportunities to consider and design programmes that address how, and in what ways, masculinities are taken into account. Data collected for the States of Fragility 2020 report (OECD, 2020[1]) point to significant challenges in the gender aspects of fragility across the 57 contexts featured in the 2020 assessment. However, the paper also suggests that increasing attention to gender within fragility can offer important opportunities to advance understanding of and responses to gender inequality and fragility. In light of the COVID-19 pandemic - and the ways in which it is likely to deepen gender-related fragility challenges - seizing these opportunities has become even more significant and pressing.

While it is true that COVID-19 has stalled, or reversed, many advances made towards gender equality and the SDGs, the political momentum to achieve gender equality within the Decade of Action has not dissipated. In line with the $20^{\text {th }}$ anniversary of the United Nations Security Council Resolution (UNSCR) 1325 and following the corporate evaluation of the National Action Plans (NAPs) to implement the Women, Peace and Security (WPS) Agenda (UN Women, 2020[53]), the global desire to effectively implement this agenda remains strong (OECD and UN Women, 2021 $\left.{ }_{[54]}\right)$. Understanding the dynamics of gender inequality in a range of contexts is vital, as the pandemic has left women suffering sharply rising levels of violence across societies, disproportionate job loss and related social protection gaps, and the downward spiral of poverty and exclusion.

The OECD can play a significant role in enabling such steps going forward. Additionally, the OECD Development Assistance Committee (DAC) Network on Gender Equality (GenderNet) and the International Network on Conflict and Fragility (INCAF) offer useful platforms for peer learning and policy dialogue among different stakeholders. Joint analysis and policy dialogue between these Networks provide opportunities to advance gender equality in fragile contexts and for more closely linking this with the women, peace and security agenda. Forthcoming revisions of the assessment methodology of the OECD Fragility Framework may provide opportunities to advance discussion and thought leadership on these issues.

In addition, the 2021 interim review of the implementation of the OECD DAC Recommendation on the Humanitarian-Development-Peace Nexus (HDP Nexus) will also look into gender equality aspects (OECD, 2021, Forthcoming $\left.{ }_{[5]}\right)$. By further defining and integrating gender-sensitive approaches across the HDP Nexus, donors can bridge the gap between the WPS Agenda and the aim of the HDP Nexus; they can enable a whole of society approach by ensuring that gender equality is mainstreamed throughout programme design and implementation; and they can ensure that commitments to "do no harm" are fully integrated into organisational practice. 


\section{References}

Bigio, J. et al. (2021), Women's participation in peace processes, Council on Foreign Relations, http://cfr.org/women-peace (accessed on March 2021).

Caprioli, M. (2005), "Primed for Violence: The Role of Gender Inequality in Predicting Internal Conflict", International Studies Quarterly, Vol. 49/2, pp. 161-178.

Caprioli, M. and M. Boyer (2001), "Gender, Violence, and International Crisis”, Journal of Conflict Resolution, Vol. 45.

Cowper-Coles, M. (2020), Women political Leaders: the impact of gender on democracy, The Global Institute for Women's Leadership, https://www.kcl.ac.uk/giwl/assets/women-politicalleaders.pdf.

Demeritt, J., A. Nichols and E. Kelly (2014), "Female Participation and Civil War Relapse", Civil Wars, Vol. 16/3, https://doi.org/10.1080/13698249.2014.966427.

Economist Intelligence Unit (2020), Democracy Index 2019, https://www.eiu.com/topic/democracy-index (accessed on 25 May 2020).

FAO (2016), Women hold the key to building a world free from hunger and poverty, http://www.fao.org/news/story/en/item/460267/icode/\#: :text=Less $\% 20$ than $\% 2020 \% 25 \% 20$ of \%20the, million $\% 20$ due $\% 20$ to $\% 20$ productivity $\% 20$ gains.

Fearon, J. and A. Hoeffler (2014), Benefits and Costs of the Conflict and Violence Targets for the Post-2015 Development Agenda, Copenhagen Consensus Centre.

Forichon, K. (2020), Considering human capital in a multi-dimensional analysis of fragility, OECD Publishing, https://doi.org/10.1787/430770d4-en.

Hamadani, J. et al. (2020), "Immediate impact of stay-at-home orders to control COVID-19 transmission on socioeconomic conditions, food insecurity, mental health, and intimate partner violence in Bangladeshi women and their families: an interrupted time series", The Lancet, Global Health, Vol. 8/11, https://doi.org/10.1016/S2214-109X(20)30366-1.

Htun, M. and S. Weldon (2018), The Logics of Gender Justice: State Action on Women's Rights Around the World, Cambridge University Press.

Htun, M. and S. Weldon (2012), "The civic origins of progressive policy change: combating violence against women in global perspective", American Political Science Review, Vol. 106/3. 
Jones, N. et al. (2020), 'I have nothing to feed my family...' Covid-19 risk pathways for adolescent girls in low- and middle-income countries., https://www.gage.odi.org/wpcontent/uploads/2020/08/Covid-19-risk-pathways-for-adolescent-girls-1.pdf.

Justino, P. et al. (2012), Women Working for Recovery: The Impact of Female Employment on Family and Community Welfare after Conflict, UN Women.

Justino, P. et al. (2012), "Quantifying the Impact of Women's Participation in Post-Conflict Recovery", Households in Conflict Network Working Paper, Vol. 131, https://opendocs.ids.ac.uk/opendocs/handle/20.500.12413/3221.

Marphatia, A. et al. (2016), "Associations of gender inequality with child malnutrition and mortality across 96 countries", Global Health, Epidemiology and Genomics, Vol. 1/6, http://dx.doi.org/doi:10.1017/gheg.2016.1.

McKinsey Global Institute (2020), COVID-19 and gender equality: Countering the regressive effects, https://www.mckinsey.com/featured-insights/future-of-work/covid-19-and-genderequality-countering-the-regressive-effects.

McKinsey Global Institute (2015), The Power of Parity: How advancing women's equality can add $\$ 12$ trillion to global growth.

Melander, E. (2005), "Gender Equality and Intrastate Armed Conflict", International Studies Quarterly, Vol. 49.

Mlambo-Ngcuka, P. (2020), Violence against women and girls: the shadow pandemic.

OECD (2021), Development finance for gender equality and women's empowerment: A 2021 snapshot, OECD, http://www.oecd.org/development/gender-development/Developmentfinance-for-gender-equality-2021.pdf.

OECD (2020), 20th Anniversary of UN Security Council Resolution 1325: Financing gender equality in fragile contexts, OECD, http://www.oecd.org/development/genderdevelopment/OECD-Gendernet-Financing-UNSCR.pdf.

OECD (2020), COVID-19 crisis in the MENA region: impact on gender equality and policy responses, OECD Publishing, Paris, https://dx.doi.org/10.1787/ee4cd4f4-en.

OECD (2020), "Politically informed approaches to working on gender equality in fragile and conflict-affected contexts", OECD Development Policy Papers, No. 32, OECD Publishing, Paris, https://dx.doi.org/10.1787/fcc94bc5-en.

OECD (2020), Response, recovery and prevention in the coronavirus (COVID-19) pandemic in developing countries: Women and girls on the frontlines, OECD Publishing, http://www.oecd.org/coronavirus/policy-responses/response-recovery-and-prevention-in-thecoronavirus-covid-19-pandemic-in-developing-countries-women-and-girls-on-the-frontlines23d645dal.

OECD (2020), SIGI 2020 Regional Report for Latin America and the Caribbean, Social Institutions and Gender Index, OECD Publishing, Paris, https://dx.doi.org/10.1787/cb7d45d1en.

OECD (2020), States of Fragility 2020, OECD Publishing, Paris, 
OECD (2019), "Engaging with men and masculinities in fragile and conflict-affected states", OECD Development Policy Papers, No. 17, OECD Publishing, Paris, https://dx.doi.org/10.1787/36e1bb11-en.

OECD (2018), Development Co-operation Report 2018: Joining Forces to Leave No One Behind, OECD Publishing, Paris, https://dx.doi.org/10.1787/dcr-2018-en.

OECD (2017), "Gender equality and women's empowerment in fragile and conflict-affected situations : A review of donor support", OECD Development Policy Papers, No. 8, OECD Publishing, Paris, https://dx.doi.org/10.1787/b75a1229-en.

OECD (2021, Forthcoming), Gender equality across the Humanitarian-Development-Peace Nexus.

OECD and UN Women (2021), Partnerships for Implementing Impact-Driven National Action Plans on Women, Peace and Security in the context of COVID-19, https://s3-eu-west1.amazonaws.com/upload.teamup.com/2487162/Gy1gVZ4Qkmpi3RwMJBaw Concept20note-20and-20agenda.pdf.

OECD DAC (2019), DAC Recommendation on Ending Sexual Exploitation, Abuse, and Harassment in Development Co-operation and Humanitarian Assistance, https://www.oecd.org/development/gender-development/dac-recommendation-on-endingsexual-exploitation-abuse-and-harassment.htm.

Paffenholz, T. et al. (2015), Making women count - not just counting women, https://www.unwomen.org/en/digital-library/publications/2017/5/making-women-count-notjust-counting-women\#view.

Parkes, J. et al. (2020), "Young People, Inequality and Violence During the COVID-19 Lockdown in Uganda.", SocArXiv, http://dx.doi.org/10.31235/osf.io/2p6hx.

Radi, S. (2020), "The Impact of COVID-19 on Vulnerable Women in the Federal Republic of Nigeria with Regard to Domestic Violence and Rape", International Journal of Innovative Science and Research Technology, Vol. 5/11, https://ijisrt.com/assets/upload/files/IJISRT20NOV220.pdf.pdf.

Schuck, A. (2018), "Women in Policing and the Response to Rape: Representattive Bureaucracy and Organizational Change", Feminist Criminology, Vol. 13/3, https://doi.org/10.1177/1557085117753668.

SIGI (2021), Social Institutions and Gender Index Database, https://stats.oecd.org/Index.aspx?DataSetCode=GIDDB2019 (accessed on 10 February 2021).

Somalia (2020), Somali Women Forging Alliances to Safeguard Equal Rights for All, Federal Government of Somalia, https://mwhrd.gov.so/en/wp-content/uploads/2020/10/SomaliWomen-Forging-Alliance-Report-October-2020-1.pdf.

True, J. (2012), The Political Economy of Violence Against Women, Oxford University Press.

UN Women (2020), Corporate Evaluation of UN Women's Support to National Action Plans on Women, Peace and Security, https://gate.unwomen.org/Evaluation/Details?evaluationld=11489. 
UN Women (2020), From Insight to Action: Gender Equality in the Wake of COVID-19.

UN Women (2015), Preventing Conflict, Transforming Justice, Securing the Peace: A global study on the implementation of the United Nations Security Council resolution 1325, https://wps.unwomen.org/pdf/en/GlobalStudy EN Web.pdf.

UN Women (2011), Progress of the World's Women: In Pursuit of Justice.

UN Women (n.d.), COVID-19 Global Gender Response Tracker, https://data.undp.org/gendertracker/.

UN Women (n.d.), Women count.

UNGA (2020), Intensification of efforts to eliminate all forms of violence against women and girls, https://undocs.org/en/A/75/274.

UNSC (2011), UN strategic results framework on women, peace and security: 2011-2020, https://www.unwomen.org/en/docs/2011/7/un-strategic-results-framework-on-women-peaceand-security.

UNSG (2016), Leave no one behind. A call to action for gender equality and women's empowerment., UN Secretary General's High-Level Panel on Women's Economic Empowerment.

WHO (2021), Devastatingly pervasive: 1 in 3 women globally experience violence, https://www.who.int/news/item/09-03-2021-devastatingly-pervasive-1-in-3-women-globallyexperience-violence.

WHO (2021), Violence against women prevalence estimates, 2018, World Health Organization, on behalf of the United Nations Inter-Agency Working Group on Violence Against Women Estimation and Data (UNICEF, UNFPA, UNODC, UNSD, UNWomen).

World Bank (2020), Women, Business, and the Law 2020, World Bank, https://openknowledge.worldbank.org/handle/10986/32639.

World Bank and FAO (2009), International Fund for Agriculture Development, World Bank, https://openknowledge.worldbank.org/handle/10986/6603.

Wright, H. (2014), Masculinities, conflict and peacebuilding: Perspectives on men through a gender lens, Saferworld.

Yasin, D. (2019), Will 2020 be a turning point for women and girls in Somalia?, IPI Global Observatory. 


\section{Notes}

${ }^{1}$ Fragility results from the combination of risk and insufficient coping capacity to manage, absorb, or mitigate those risks. For full definition and methodology employed to measure fragility see www3.compareyourcountry.org/states-of-fragility/about/0/.

2 While work has focused on the relationship between gender and individuals aspects of dimensions of fragility, such as corruption, for example, this is rarely understood as part of/connected to wider discussions of fragility.

${ }^{3}$ Figures and estimates for fragile and extremely fragile contexts where calculated based on data published in the cited report.

${ }^{4}$ For examples, see for instance E. Pearson, Demonstrating Legislative Leadership: The Introduction of Rwanda's Gender-Based Violence Bill, Inclusive Security, April 2008. https://www.inclusivesecurity.org/publication/demonstrating-legislative-leadership-the-introduction-ofrwandas-gender-based-violence-bill/: Ahikire, J. and Mwiine, A. A. (2015). The politics of promoting gender equity in contemporary Uganda: Cases of the Domestic Violence Law and the policy on Universal Primary Education. ESID Working Paper No. 55. Manchester, UK: University of Manchester (ISBN: 978-1-90874955-0); The Westminster Foundation for Democracy and Global Institute for Women's Leadership at King's College London (2020), Women political leaders: the impact of gender on democracy. https://www.kcl.ac.uk/giwl/assets/women-political-leaders.pdf.

${ }^{5}$ For a brief overview see for example, UNDP, Overview of linkages between gender and climate change, Gender and Climate Change, Asia and the Pacific, Policy Brief 1, 2013.

${ }^{6}$ This means that a husband can prevent his wife from getting a job or if permission or additional documentation is required for a woman to work but not a man. This statement also holds true if it is considered a form of disobedience with legal consequences, such as loss of maintenance, for a woman to work contrary to her husband's wishes or the interests of the family.

${ }^{7}$ There is no data available for this statement in Syria.

${ }^{8}$ The economic and productive sectors have been selected for this analysis because they are essential for women's economic empowerment. The 11 economic and productive sectors, based on a number of purpose codes in the OECD Creditor Reporting System, used for this analysis are agriculture and rural development; banking and business; communication; employment policy; energy; industry; mining, construction and tourism; public finance management; trade; transportation and storage; and urban development.

${ }^{9}$ See www.oecd.org/dac/financing-sustainable-development/development-finance-data/.

${ }^{10}$ Bilateral allocable ODA.

11 For analysis of effects of COVID-19 on women and girls specifically in fragile and conflict-affected settings see e.g. Caren Grown and Franck Bousquet, 'Gender inequality exacerbates the COVID-19 crisis in fragile and conflict-affected settings, World Bank Blogs, July 92020 , https://blogs.worldbank.org/dev4peace/gender-inequality-exacerbates-covid-19-crisis-fragile-and-conflictaffected-settings. Deqa Yasin Hagi Yusuf, 'In the battle against COVID-19, women make Somalia stronger', Devex, 01 June 2020, https://www.devex.com/news/opinion-in-the-battle-against-covid-19women-make-somalia-stronger-97345. 


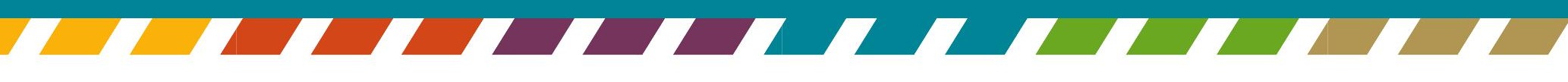

